\title{
Short- and long-term exposure to trace metal(loid)s from the production of ferromanganese alloys by personal sampling and biomarkers
}

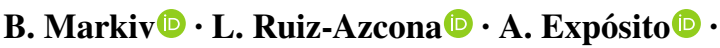 \\ M. Santibáñez $\mathbb{B}$ I. Fernández-Olmo
}

Received: 15 November 2021 / Accepted: 27 January 2022 / Published online: 22 February 2022

(C) The Author(s) 2022

\begin{abstract}
The environmental exposure to trace metal(loid)s (As, $\mathrm{Cd}, \mathrm{Cu}, \mathrm{Fe}, \mathrm{Mn}, \mathrm{Pb}$, and $\mathrm{Zn}$ ) was assessed near a ferromanganese alloy plant using filters from personal particulate matter (PM) samplers (bioaccessible and non-bioaccessible fine and coarse fractions) and whole blood as short-term exposure markers, and scalp hair and fingernails as long-term biomarkers, collected from volunteers $(n=130)$ living in Santander Bay (northern Spain). Bioaccessible and non-bioaccessible metal(loid) concentrations in coarse and fine PM from personal samplers were determined by ICP-MS after extraction/digestion. Metal(loid) concentration in biomarkers was measured after alkaline dilution (whole blood) and acid digestion (fingernails and scalp hair) by ICP-MS as well. Results were discussed in terms of exposure, considering the distance to the main Mn source, and sex. In terms of exposure, significant differences were found for $\mathrm{Mn}$ in all the studied fractions of PM, As in whole blood, $\mathrm{Mn}$ and $\mathrm{Cu}$ in scalp hair and $\mathrm{Mn}$ and $\mathrm{Pb}$
\end{abstract}

Supplementary Information The online version contains supplementary material available at https://doi. org/10.1007/s10653-022-01218-8.

B. Markiv $(\bowtie) \cdot$ A. Expósito · I. Fernández-Olmo

Departamento de Ingenierías Química y Biomolecular, Universidad de Cantabria, Santander, Spain

e-mail:markivb@unican.es

L. Ruiz-Azcona $\cdot$ M. Santibáñez

Departamento de Enfermería, Universidad de Cantabria,

Santander, Spain in fingernails, with all concentrations being higher for those living closer to the Mn source, with the exception of $\mathrm{Cu}$ in scalp hair. Furthermore, the analysis of the correlation between Mn levels in the studied biomarkers and the wind-weighted distance to the main source of Mn allows us to conclude that scalp hair and mainly fingernails are appropriate biomarkers of long-term airborne $\mathrm{Mn}$ exposure. This was also confirmed by the significant positive correlations between scalp hair $\mathrm{Mn}$ and bioaccessible $\mathrm{Mn}$ in coarse and fine fractions, and between fingernails $\mathrm{Mn}$ and all PM fractions. This implies that people living closer to a ferromanganese alloy plant are exposed to higher levels of airborne metal(loid)s, mainly Mn, leading to higher levels of this metal in scalp hair and fingernails, which according to the literature, might affect some neurological outcomes. According to sex, significant differences were observed for $\mathrm{Fe}, \mathrm{Cu}$ and $\mathrm{Pb}$ in whole blood, with higher concentrations of $\mathrm{Fe}$ and $\mathrm{Pb}$ in males, and higher levels of $\mathrm{Cu}$ in females; and for $\mathrm{Mn}, \mathrm{Cu}, \mathrm{Zn}, \mathrm{Cd}$ and $\mathrm{Pb}$ in scalp hair, with higher concentrations in males for all metal(loid)s except $\mathrm{Cu}$.

Keywords Biomarkers - Manganese $\cdot$ Trace metal(loid)s · Ferromanganese alloy production . Environmental exposure 


\section{Introduction}

Exposure to elevated levels of metal(loid)s that are present in the environment is concerning due to the resulting adverse health effects (carcinogenic, neurotoxic, etc.), even if some of them can be considered as essential, required at trace levels for metabolism, such as copper $(\mathrm{Cu})$, iron $(\mathrm{Fe})$, manganese $(\mathrm{Mn})$ or zinc (Zn) (Maret, 2016; Zoroddu et al., 2019). Three main routes of exposure to metal(loid)s are known: (i) ingestion from foods and water; (ii) dermal contact; and (iii) inhalation.

The inhalation route of exposure is particularly important for people living close to airborne metal(loid)s emission sources in urban and industrial areas (Bauer et al., 2020), such as metallurgy, steelworks, combustion (including transportation) and incineration. Airborne metal(loid)s are bound to particulate matter (PM), its particle size being a key parameter on the fate of such pollutants in the human body (Kelly \& Fussell, 2012). Thus, the thoracic fraction (equivalent to $\mathrm{PM}_{10}$ ) includes the tracheobronchial fraction (i.e. inhaled particles that penetrate beyond the larynx but do not reach the non-ciliated airways) and the respirable fraction (i.e. inhaled particles that enter the non-ciliated airways). Particles of the $2.5-10 \mu \mathrm{m}$ size fraction are mostly deposited in the pharyngeal and tracheal region (i.e. constitute the tracheobronchial fraction), but they can be swallowed, reaching the gastrointestinal tract, where they come into contact with gastric juice. Smaller particles (i.e. the respirable fraction) can travel deeper into the alveolar region of the lungs, where they interact with the lung fluid; the interstitial lung fluid has a neutral $\mathrm{pH}$; however, these small particles can be phagocytosed by alveolar macrophages, resulting in a more acidic medium ( $\mathrm{pH} 4.5$ ). Dissolved metal(loid)s can then reach the circulatory system (Expósito et al., 2021; Mukhtar \& Limbeck, 2013).

A simple marker of the exposure to metal(loid) $\mathrm{s}$ by inhalation route is the distance between the known source(s) and the receptors; for example, previous studies have used the distance between the participants' home in cross-sectional epidemiological studies and the source of emission of certain air pollutants as a preliminary indicator of exposure (Vimercati et al., 2016; Zubero et al., 2010). The importance of being downwind or upwind of the emission source has been considered by Haynes et al. (2012), calculating the wind direction-weighted distance for short-term exposure, addressing Mn exposure in the vicinity of a Mn alloy plant by children living in the town of Marietta (Ohio) in the USA.

The assessment of the exposure to metal(loid)s by the inhalation route can be done directly by measuring or modelling their levels in ambient air, or indirectly by measuring their concentration in selected biomarkers. Stationary samplers have been widely used in extensive PM sampling campaigns for the analysis of metal(loid)s concentration in filters, providing information about the long-term exposure to such pollutants, but with the limitation of obtaining information only from specific sites where these samplers were located (Fulk et al., 2016). This limitation is addressed using personal PM samplers, which are easy to wear by exposed individuals, with the added advantage of accounting for changes in exposure during short sampling periods. Filters collected from these samplers can be analysed for total metal(loid)s content or for the bioaccessible concentration, which reflects the amount of each pollutant to be solubilised by a human synthetic fluid.

The degree of inhalation exposure can also be determined by the analysis of specific exposure biomarkers (Fernández-Olmo et al., 2021). However, the levels of metal(loid)s in such biomarkers can also account for the other routes of exposure, mainly the ingestion route; this is especially true for essential trace elements, which are included in the usual diet, but can sometimes also apply to non-essential ones, such as arsenic (As), cadmium $(\mathrm{Cd})$ or lead $(\mathrm{Pb})$. The usefulness of an exposure biomarker is assessed for its ability to characterise and differentiate exposed and non-exposed groups, as well as for their ability to predict health disorders, anticipating any deterioration of health (Viana et al., 2014; Zheng et al., 2011). Although there is no current consensus on which biomarker best defines the dose-effect relationship, and furthermore, the use of these biomarkers does not differentiate how much of these metal(loid)s enter the body by inhalation, biomarkers of exposure have been used in epidemiological studies designed to assess the exposure to some metal(loid)s near airborne metal(loid)s sources (Haynes et al., 2015; Rodrigues et al., 2018; Viana et al., 2014).

Blood has been considered as a short-term exposure biomarker to some metal(loid)s (Freire et al., 2015; Stojsavljević et al., 2019); it was frequently 
used to assess exposure to non-essential metals such as $\mathrm{Pb}$ and $\mathrm{Cd}$ (Henríquez-Hernández et al., 2017; Wong \& Lye, 2008), highlighting the possibility of assessing acute intoxications due to the efficiency and sensitivity of the use of this biomarker. However, there are doubts about its use to assess exposure to essential trace elements such as $\mathrm{Mn}, \mathrm{Fe}, \mathrm{Cu}$ or $\mathrm{Zn}$, due to their homeostatic regulation. For example, the mean-life time of $\mathrm{Mn}$ in blood is much shorter than in other tissues and cellular compartments, so some authors consider that it is not a good biomarker of short-term exposure to Mn (Jiang et al., 2007; Kim et al., 2015), being this more noticeable in the case of inhalation exposure, since despite finding higher levels in the blood of occupationally exposed individuals, it is difficult to quantify how the pulmonary uptake of airborne Mn contributes to its increase in blood (Roth, 2006).

Other candidates have been considered for longterm exposure to metal(loid)s, such as hair and nails (Butler et al., 2019; Fernández-Olmo et al., 2021; Nakaona et al., 2020; Parhizkar et al., 2021), because of their slow growth: between 1 and $1.2 \mathrm{~cm} /$ month of hair (Van Neste \& Rushton, 2016) and about $3.47 \mathrm{~mm} / \mathrm{month}$ of fingernails (Yaemsiri et al., 2010). They are easy to sample, transport, handle and store (Haynes et al., 2015; Menezes-Filho et al., 2009; Sukumar \& Subramanian, 2007), although it is not possible to discriminate between the specific exposure route to them, providing us with a final concentration resulting from inhalation, oral and dermal routes. When considering these biomarkers, it is necessary to be cautious about the use of cosmetics such as dyes or nail polishes. Although Directive $1223 / 2009$ on cosmetic products forbids the use of heavy metals as additives in EU member states (European Parliament \& Council of the European Union, 2009), a recent study has pointed out that coloured nail polish still contains some metal(loid)s (Ceballos et al., 2021).

Recent studies published by our research group highlighted the elevated levels of airborne $\mathrm{Mn}$ in Santander Bay (Cantabria region, Northern Spain), exceeding the WHO annual guideline (i.e. $150 \mathrm{ng} /$ $\mathrm{m}^{3}$ of Mn) (Hernández-Pellón \& Fernández-Olmo, 2019; Hernandez-Pellón et al., 2017). These elevated levels were mainly due to the emissions from a ferromanganese alloy production plant located in this area; approximately, $91 \%$ of air $\mathrm{Mn}$ emitted in this area comes from this factory (Otero-Pregigueiro et al., 2018). In addition, a source apportionment study carried out in this area also identified $\mathrm{Cd}, \mathrm{Fe}, \mathrm{Pb}$ and $\mathrm{Zn}$ as tracers from this plant (Hernández-Pellón \& Fernández-Olmo, 2019). However, other local sources of metal(loid)s apart from the ferromanganese alloy exist, such as road traffic, combustion and other industrial sources, leading to moderate levels of $\mathrm{Cu}$ and As (Hernández-Pellón \& Fernández-Olmo, 2019).

Therefore, this area was selected to assess the exposure to airborne $\mathrm{Mn}$ and other trace metal(loid) $s$ in the healthy adult population living in the vicinity of this ferromanganese alloy plant. For this purpose, the following short-term exposure markers to such metal(loid)s were taken from 130 volunteers recruited in a cross-sectional study: 24-h personal PM samples of different particle sizes $\left(\mathrm{PM}_{10-2.5}\right.$ and $\left.\mathrm{PM}_{2.5}\right)$, which accounted for the inhalation route of exposure, as well as whole blood samples. For long-term exposure, scalp hair and fingernails samples were collected, with the aim of finding associations between the amounts of metal(loid)s inhaled and those processed by the body, to determine the best biomarker of exposure to airborne $\mathrm{Mn}$ and other metal(loid)s.

\section{Methodology}

Study area and population

The study was carried out in Santander Bay, Cantabria, Northern Spain (about 250,000 inhabitants in 2019). Among the local industrial sources of metal(loid)s in this area, a ferromanganese alloy plant is the main emitter of metal(loid)s, mainly of $\mathrm{Mn}$ as reported by Otero-Pregigueiro et al. (2018), outstanding relatively high levels of $\mathrm{Mn}$ in ambient air that frequently exceeded the WHO guideline value (150 $\mathrm{ng} / \mathrm{m}^{3}$, annual mean) in the town of Maliaño (about 10,000 inhabitants), where the ferromanganese alloys smelter is located (Hernández-Pellón \& Fernández-Olmo, 2019).

Volunteers were recruited as specified in RuizAzcona et al. (2021). All volunteers considered in this study were over 18 years old, and without previous or current work in relation with the ferromanganese plant or any other occupational exposure to $\mathrm{Mn}$. All of them resided for a minimum of one year in 
Santander Bay at different distances from the ferroalloy factory, which was intentionally placed in Fig. 1 in the centre of the exposure area, to account for the degree of exposure to $\mathrm{Mn}$ and the other studied metal(loid)s. The study population was then divided into highly exposed (distance less than $1.5 \mathrm{~km}$ between each volunteer's residence and the Mn alloy plant, i.e. those living in Maliaño, where the main $\mathrm{Mn}$ source is located) and moderately exposed (distance greater than $1.5 \mathrm{~km}$, i.e. those living outside Maliaño, mainly in the city of Santander).

The study was approved by the ethical committee of clinical research in Cantabria (CEIC) and by the ethical committee of research of the University of Cantabria (CEUC).

Written informed consent was obtained from each subject and whole blood, scalp hair and fingernails collection was performed only after permission was obtained. In addition to biological samples, PM samples were obtained from personal samplers that were worn for $24 \mathrm{~h}$ by each volunteer. Subjects were asked to complete a structured questionnaire containing socio-demographic characteristics, health and medication status, occupational data, smoking habits, dietary habits including daily intake of Mn-rich foods and $\mathrm{Mn}$ food supplements, alcohol consumption and other lifestyles. The sampling campaign started in November 2019 and ended in November 2020 (interrupted from March 2020 to June 2020 due to the COVID-19 outbreak), concluding the sampling campaign with a total of 130 volunteers.

\section{Sample preparation}

All the used reagents for treatment and sample preparation were of analytical grade provided by Merck and PanReac AppliChem (Darmstadt, Germany). Whole blood samples of approximately $7.5 \mathrm{~mL}$ were collected by venipuncture after disinfection of the skin with $70 \%$ alcohol, collected in lithium heparin monovettes developed for metal determination (Sarstedt, Nümbrecht, Germany). These samples were refrigerated for up to 14 days until dilution with an alkaline solution $(2 \%(\mathrm{w} / \mathrm{v})$ 1-butanol, $0.05 \%(\mathrm{w} / \mathrm{v})$ EDTA, $0.05 \%(\mathrm{w} / \mathrm{v})$ triton $\mathrm{X}-100$ and $\left.1 \%(\mathrm{w} / \mathrm{v}) \mathrm{NH}_{4} \mathrm{OH}\right)$ as described in González-Antuña et al. (2017) at a minimum whole blood/alkaline solution ratio of $1 / 10$ (w/w), and subsequent analysis by ICP/MS. Scalp hair and fingernail samples were collected in polypropylene flasks using clean ceramic scissors and nail clippers, respectively. A tuft of hair was cut from the occipital part of the head, using the $2 \mathrm{~cm}$ closest to

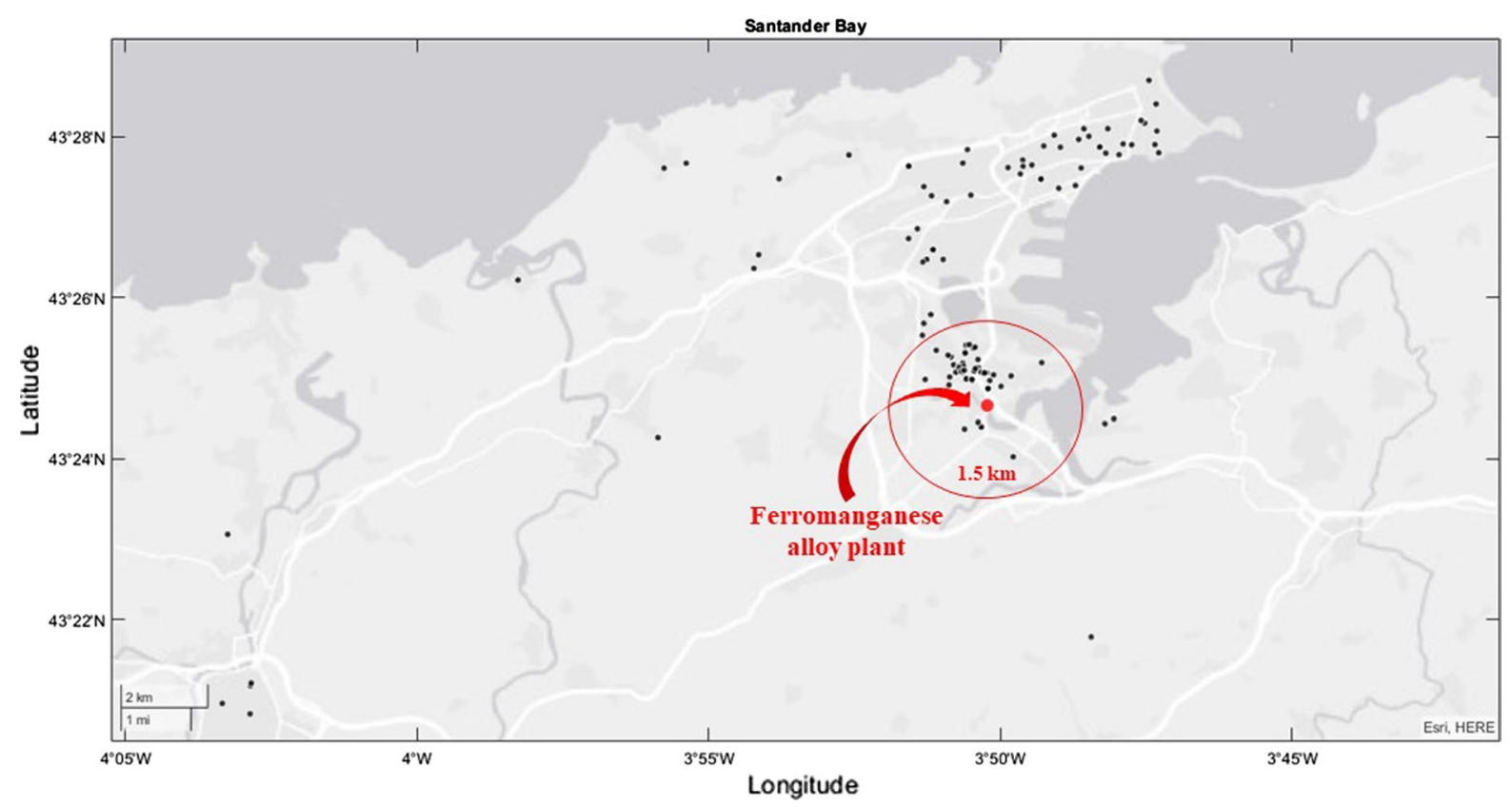

Fig. 1 Location of participants' residence and the Mn alloy plant 
the scalp for analysis. By using only $2 \mathrm{~cm}$ from the root of the hair, alterations in hair morphology due to dyes are eliminated. This is because the hair tips may contain higher levels of metals since the hair further from the root has longer contact with the environment and additional dye applications. Each additional dye application process leads to a higher level of oxidation of the hair, thus creating more potential binding sites, and together with the additional mechanical wear that occurs when moving from root to tip, can facilitate the diffusion of dyes into the hair (Godfrey et al., 2013).

Fingernails of both hands were cut after asking the volunteers to wash them with the liquid soap provided and to rinse them thoroughly with tap water. Females were asked whether they dyed their hair and/or polished their fingernails. When they polished them, the polish residues were removed using acetone before cutting, and the fingernails were sonicated for $10 \mathrm{~min}$ before proceeding to the washing protocol. Scalp hair and fingernails were washed according to the washing protocol described in Eastman et al. (2013), thus removing all exogenous metals and ensuring that only endogenous metals were quantified. Once cleaned, samples were microwave digested (Milestone, Ethos One) at $200{ }^{\circ} \mathrm{C}$ in a $4 / 1(\mathrm{v} / \mathrm{v}) \mathrm{HNO}_{3} / \mathrm{H}_{2} \mathrm{O}_{2}$ solution, and finally analysed by ICP/MS.

A personal two-stage modular impactor (SKC PMI coarse) was used to collect $\mathrm{PM}_{2.5}$ and $\mathrm{PM}_{10-2.5}$ samples for $24 \mathrm{~h}$, connected to a personal pump (SKC Aircheck XR5000) operating at a flow rate of $3 \mathrm{lpm}$. PTFE filters of $37 \mathrm{~mm}$ ( $1 \mu \mathrm{m}$ pore size) were used for the $\mathrm{PM}_{2.5}$ fraction, and PTFE filters of $25 \mathrm{~mm}$ $(1 \mu \mathrm{m}$ pore size $)$ were used for the $\mathrm{PM}_{10-2.5}$ fraction (SKC Inc., Houston, USA). An in vitro bioaccessibility test was performed by extracting each filter with $10 \mathrm{~mL}$ of ALF (Artificial Lysosomal Fluid) as lung fluid for $24 \mathrm{~h}$ for $\mathrm{PM}_{2.5}$ filters, and gastric fluid for $1 \mathrm{~h}$ for $\mathrm{PM}_{10-2.5}$ filters, in an incubation system (MRHX$04, \mathrm{LSCI}$ ) at $37{ }^{\circ} \mathrm{C}$ with end-to-end rotation (SBS) at $30 \mathrm{rpm}$. After the leaching assay, the samples were centrifuged (Mistasel-BL/Selecta) and the supernatants were filtered using polypropylene syringe filters with a pore size of $0.45 \mu \mathrm{m}$. The choice of fluids and composition is described in detail in Expósito et al. (2021). Then, the insoluble fraction (non-bioaccessible fraction) was digested based on the European standard method "EN-UNE 14,902:2006", which consisted of an acid digestion of each filter in a $\mathrm{HNO}_{3} /$
$\mathrm{H}_{2} \mathrm{O}_{2}$ solution in a $4 / 1(\mathrm{v} / \mathrm{v})$ ratio, up to $220{ }^{\circ} \mathrm{C}$. The ALF extracts were stored until analysis at $4{ }^{\circ} \mathrm{C}$ for a maximum of $48 \mathrm{~h}$.

\section{Metal(loid) analysis}

Mass spectrometry inductively coupled plasma (ICP/ MS, Agilent $7500 \mathrm{CE}$ ) was used for the analysis of ${ }^{55} \mathrm{Mn},{ }^{56} \mathrm{Fe},{ }^{63} \mathrm{Cu},{ }^{66} \mathrm{Zn},{ }^{75} \mathrm{As},{ }^{111} \mathrm{Cd}$ and ${ }^{207} \mathrm{~Pb}$ in the different samples. Internal standards $\left({ }^{89} \mathrm{Y},{ }^{103} \mathrm{Rh}\right.$ and ${ }^{185} \mathrm{Re}$ ) were added to each vial to correct for instrumental drifts, and a collision cell with a helium flow rate of $4.8 \mathrm{~mL} / \mathrm{min}$ was used to minimise spectral interferences. Since whole blood, ALF and gastric fluid can cause spectral and non-spectral interferences (matrix effects) during ICP/MS analysis, the determination of the concentration of the metals studied in these samples was performed by adding the same solution to the Multi-Element Standard Solution used to calibrate the instrument. In the case of samples from acid digestion, the calibration standards were simply prepared in dilute nitric acid (1 N). Seven calibration points between 0 and $25 \mathrm{ppb}$ were used and samples were diluted when necessary.

Limits of detection (LOD) were calculated based on the variability of 10 procedural blanks (two-tailed Student's $t$-test with $95 \%$ confidence for $n-1$ samples (2.26) times the standard deviation of the blanks), being constant for each metal(loid) for whole blood and filters, and variable for scalp hair and fingernails, depending on the weight of sample from each volunteer. Limit of quantification was determined as 10 times the SD of blanks (Al-Hakkani, 2019) (see Supplementary Table 1). Measurements of these procedural blanks also allowed checking for possible contamination of containers and reagents. The mean values of the studied metal(loid)s measured in these blanks were subtracted from all samples except for whole blood because both calibration points and samples were prepared in the same solution. Results were presented for elements with a minimum of $50 \%$ of the samples above the limit of detection.

The analytical methods described were validated using certified reference material for whole blood and human hair (Seronorm ${ }^{\mathrm{TM}}$ Trace Elements Whole Blood L-1 and ERM®-DB001, respectively), but no reference material was found for fingernails. The recoveries obtained for the different certified metal(loid)s range from 94 to $110 \%$ for whole blood 
and from 93 to $110 \%$ for hair (see Supplementary Table 2). A worse recovery was obtained for $\mathrm{Mn}$ in hair (144\%), but its metal content was not certified in ERM®-DB001, because only one laboratory provided results on hair Mn concentration. The digestion method was validated in the research group as described in Hernández-Pellón et al. (2018). In addition to the use of certified reference materials, after calibration and at the end of each analytical run, quality control standards covering the concentration range of interest were measured to check the accuracy of the measurements.

Wind-weighted distance calculation procedure for exposure metrics

To study the correlation between the levels of metal(loid)s in the short-term markers (whole blood and $\mathrm{PM}$ ) and the distance between each volunteer's residence and the main metal(loid) source weighted by wind, hourly wind data were taken for the personal sampling time slots of each subject. For this purpose, hourly wind direction and speed data from the Santander-Parayas Airport weather station provided by Openair thorough the World Met package ( $\mathrm{R}$ version 4.0.5) were used.

The procedure described by Haynes et al. (2012) was followed to calculate the wind-weighted source/ home distance. First, Wind Index (WI), a parameter between $0-1$ indicating whether the subject is upwind (0) or downwind (1) of the source, was calculated, according to Eq. (1), where $\alpha_{\text {homesource }}$ is the direction of the home from the source (rad) and $\theta_{\mathrm{m}}$ represents the average wind direction at the selected meteorological station in the sampling period in which the volunteer wore the personal sampler (rad):

$\mathrm{WI}=\frac{1-\cos \left(\alpha_{\text {homesource }}-\theta_{\mathrm{m}}\right)}{2}$

The average wind direction $\left(\theta_{\mathrm{m}}\right)$ was calculated from hourly data considering the wind speed. To calculate the average direction in each period, it was necessary to first determine the $U_{\text {mean }}$ and $V_{\text {mean }}$ components from Eqs. 2 and 3, where $N$ is number of hours of sampling, $u_{i}$ is the hourly wind speed $(\mathrm{m} / \mathrm{s})$ and $\theta_{i}$ is the hourly wind direction (rad).

$$
\begin{aligned}
& U_{\text {mean }}=-\frac{1}{N} \sum u_{i} \operatorname{sen}\left(\theta_{i}\right) \\
& V_{\text {mean }}=-\frac{1}{N} \sum u_{i} \cos \left(\theta_{i}\right)
\end{aligned}
$$

To obtain the average direction $\left(\theta_{\mathrm{m}}\right)$, Eq. 4 was applied (Grange, 2014), where FLOW $=+180$ when ArcTan $<180$ and FLOW $=-180$ when ArcTan $>180$ :

$\theta_{\mathrm{m}}=\operatorname{ArcTan}\left(\frac{U_{\text {mean }}}{V_{\text {mean }}}\right)+$ FLOW

Then, the weighted distance $\left(d_{\mathrm{w}}\right)$ was calculated for each subject by dividing the actual distance $(d)$ by the WI, as shown in Eq. (5).

$d_{\mathrm{w}}=\frac{d}{\mathrm{WI}}$

With respect to the long-term markers, to calculate the weighted source/home distance, wind data were taken for the months prior to fingernails and scalp hair sampling for each subject (6 months for fingernail samples and 2 months for scalp hair samples). For these longer periods, the procedure shown in Eqs. (1-5) sometimes failed, due to the lack of representativeness of the average wind direction over these periods. To address this, an alternative procedure was developed to calculate the weighted distance $\left(d^{\prime}{ }_{\mathrm{w}}\right)$, using a weighting factor $\left(w_{\mathrm{f}}\right)$ that considers the frequency with which the wind blows downwind (i.e. from the source to the residence) during the period considered for each subject. For this purpose, the area of interest was divided into 8 sectors, placing the emitting source in the centre of the area and assigning each residence a wind sector. Next, the frequency (fraction of hours) in which the wind blew from the sector opposite the volunteer's home was calculated with respect to the total number of hours. Finally, the distance between the source and the subject's home was weighted by dividing the raw distance by this weighting factor (Eq. 6).

$d_{\mathrm{w}}^{\prime}=\frac{d}{w_{\mathrm{f}}}$ 
Statistical analysis

Data analysis was performed with IBM SPSS Statistics software (version 22) and R software (version 4.0.5). Statistical analysis was only performed when at least $50 \%$ of the data above the LOD was available. For metal(loid) concentrations in biomarkers and PM samples below the LOD, a value of LOD/2 was assigned.

All quantitative variables in the study were tested for normality using the Kolmogorov-Smirnov test with Lilliefors correction, and the homogeneity of variances was tested using Levene's test. Student's $t$-test (normal distribution and homogeneity of variances), Welch's $t^{\prime}$-test (normal distribution and nonhomogeneous variances) and the Mann-Whitney $U$ test (non-normal distribution) were used to compare means/medians between the established groups.

To study the potential effect of confounders on the differences between groups as a function of source distance (i.e. highly exposed vs. moderately exposed), linear regression models were used to calculate crude and adjusted Mean Differences (MDs) of each metal(loid) concentration with their $95 \%$ confidence intervals (CI). Age (as a continuous variable), sex and study level (ordinal categorised) were pre-established as confounders and included in a first multivariate model. Also, a second multivariate model added as confounders employment status, tobacco smoking and dietary habits: Mn supplement intake and high Mn food consumption (nuts, tea $\geq 5 /$ week, fish as tunas or salmon families... $\geq 3 /$ week).

Spearman correlation coefficients were calculated between the metal(loid)s of each matrix and between the matrices for each metal(loid). Finally, correlations were also calculated between the biomarkers studied, the levels in PM and the wind-weighted distance between each volunteer's residence and the main metal(loid) source, as well as the age of the subjects. The Chi-square test was applied to determine whether there was any relationship between exposure (categorised as highly/moderately exposed) and the categorical variables used in the description of the population (sex, education level, smoking status). All tests were bilateral, and the alpha error was set at $5 \%$.

\section{Results}

Description of the study population

Table 1 shows the socio-demographic characteristics of the studied population divided according to exposure (moderately exposed/highly exposed) with an age range between 20 and 71 years, with an average of $41.75 \pm \mathrm{SD}=13.97$ years. The highly exposed population lives within a radius of $0.8 \mathrm{~km}$ $(0.25-1.5 \mathrm{~km})$ from the ferromanganese factory as the main source of contamination, while the moderately exposed population resides within an average radius of $7.3 \mathrm{~km}(2-34 \mathrm{~km})$. Significant differences were seen between exposure by years of residence, higher for the most exposed group $(p<0.001)$; by educational level, lower for the most exposed population $(p=0.005)$; and by employment status, with more people employed full time in the moderately exposed population $(p=0.045)$. However, no differences were seen by sex and smoking habits or alcohol consumption. Regarding to diet, none participant was vegetarian and the consumption of grains, greenpeas and beans was similar. Furthermore, the study population comes from an urban/industrial area, so their diet is mainly based on products purchased in supermarkets, thus ruling out the intake of potentially contaminated food grown in local soils. In addition, the ingestion of water was not considered because of the low metal(loid) content determined in local tap water. The rest of dietary characteristics are also included in Table 1.

\section{(Bio)markers}

Tables 2 and 3 show the concentration of the studied metal(loid)s by sex (arithmetic mean (AM), standard deviation (SD), median and reference values (RV) with $95 \%$ confidence interval) in the short-term (bio) markers (personal filters and whole blood), as well as in the long-term biomarkers (scalp hair and fingernails), respectively. Metal(loid)s with at least 50\% values above the LOD in each matrix are shown. Reference values were calculated for biological matrices only, as the $95^{\text {th }}$ percentile with a $95 \%$ confidence interval, as specified by Saravanabhavan et al. (2017). With respect to whole blood as short-term biomarker, significant sex differences were observed for $\mathrm{Fe}(p=0.039), \mathrm{Cu}(p=0.006)$ and $\mathrm{Pb}(p=0.001)$, 
Table 1 Socio-demographic characteristics of the study population divided according to the exposure groups (highly exposed (HE) $(\leq 1.5 \mathrm{~km})$ versus moderately exposed $(\mathrm{ME})(>1.5 \mathrm{~km})$

\begin{tabular}{|c|c|c|c|c|c|c|c|}
\hline \multirow{2}{*}{$\begin{array}{l}\text { Characteristics } \\
\text { Source distance from main point (m) }\end{array}$} & \multicolumn{2}{|c|}{$\begin{array}{l}\mathrm{ME}(>1.5 \mathrm{~km}) \\
N=65\end{array}$} & \multicolumn{2}{|c|}{$\begin{array}{l}\mathrm{HE}(\leq 1.5 \mathrm{~km}) \\
N=65\end{array}$} & \multicolumn{2}{|c|}{ Total $N=130$} & \multirow[t]{2}{*}{$p$-value } \\
\hline & & & & & & & \\
\hline Arithmetic Mean, SD & 7294.68 & 5258.64 & 799.24 & 297.94 & 4046.96 & 4938.92 & \\
\hline Geometric Mean & 6212.08 & & 747.87 & & 2155.42 & & \\
\hline Median, P95 & 6085.55 & 18782.14 & 743.19 & 1447.45 & 1770.40 & 17910.06 & \\
\hline Range: $\min , \max$ & 2040.80 & 33984.74 & 268.07 & 1500.00 & 268.07 & 33984.74 & \\
\hline Interquartile Range (P25, P75) & 4969.84 & 7254.11 & 594.43 & 946.25 & 728.56 & 6089.44 & \\
\hline \multicolumn{8}{|l|}{ Age } \\
\hline Arithmetic Mean, SD & 39.77 & 13.45 & 43.66 & 14.31 & 41.72 & 13.97 & $0.092 * *$ \\
\hline Range: $\min , \max$ & 20 & 71 & 20 & 71 & 20 & 71 & \\
\hline \multicolumn{8}{|l|}{ Years residing } \\
\hline Arithmetic Mean, SD & 11.62 & 12.42 & 18.85 & 13.96 & 15.23 & 13.65 & $<0.001 * *$ \\
\hline Range: $\min , \max$ & 1 & 60 & 1 & 71 & 1 & 71 & \\
\hline $\operatorname{Sex}(n, \%)$ & & & & & & & $0.553 *$ \\
\hline Female & 46 & $70.8 \%$ & 49 & $75.4 \%$ & 95 & $100.0 \%$ & \\
\hline Male & 19 & $29.2 \%$ & 16 & $24.6 \%$ & 35 & $100.0 \%$ & \\
\hline Studies $(n, \%)$ & & & & & & & $0.005 *$ \\
\hline Primary education & 3 & $4.6 \%$ & 3 & $4.6 \%$ & 6 & $4.6 \%$ & \\
\hline $\begin{array}{l}\text { Secondary Education/Vocational education and } \\
\text { Training }\end{array}$ & 7 & $10.8 \%$ & 15 & $23.1 \%$ & 22 & $16.9 \%$ & \\
\hline High school level/Certificate of Higher Education & 10 & $15.4 \%$ & 20 & $30.8 \%$ & 30 & $23.1 \%$ & \\
\hline University studies (Bachelor's Degree) & 8 & $12.3 \%$ & 11 & $16.9 \%$ & 19 & $14.6 \%$ & \\
\hline University studies (University Degree) & 37 & $56.9 \%$ & 16 & $24.6 \%$ & 53 & $40.8 \%$ & \\
\hline Employment status $(n, \%)$ & & & & & & & $0.045 *$ \\
\hline Employed full time & 54 & $83.1 \%$ & 43 & $66.2 \%$ & 97 & $74.6 \%$ & \\
\hline Unemployed & 1 & $1.5 \%$ & 4 & $6.2 \%$ & 5 & $3.8 \%$ & \\
\hline Housewife & 0 & & 5 & $7.7 \%$ & 5 & $3.8 \%$ & \\
\hline Retired & 7 & $10.8 \%$ & 6 & $9.2 \%$ & 13 & $10.0 \%$ & \\
\hline Full-time student & 3 & $4.6 \%$ & 7 & $10.8 \%$ & 10 & $7.7 \%$ & \\
\hline Smoking status $(n, \%)$ & & & & & & & $0.498 *$ \\
\hline Non-smoker & 42 & $64.6 \%$ & 42 & $64.6 \%$ & 84 & $64.6 \%$ & \\
\hline Former & 9 & $13.8 \%$ & 13 & $20.0 \%$ & 22 & $16.9 \%$ & \\
\hline Current & 14 & $21.5 \%$ & 10 & $15.4 \%$ & 24 & $18.5 \%$ & \\
\hline Alcohol status & & & & & & & $0.597 *$ \\
\hline Never & 34 & $52.3 \%$ & 37 & $56.9 \%$ & 71 & $54.6 \%$ & \\
\hline Ever & 31 & $47.7 \%$ & 28 & $43.1 \%$ & 59 & $45.4 \%$ & \\
\hline Average of pure ethanol (g/week) $(n, \%)$ & & & & & & & $0.245^{*}$ \\
\hline $0 \mathrm{~g} /$ week & 34 & $52.3 \%$ & 37 & $56.9 \%$ & 71 & $54.6 \%$ & \\
\hline $1-24 \mathrm{~g} /$ week & 11 & $16.9 \%$ & 11 & $16.9 \%$ & 22 & $16.9 \%$ & \\
\hline $25-74 \mathrm{~g} /$ week & 16 & $24.6 \%$ & 17 & $26.2 \%$ & 33 & $25.4 \%$ & \\
\hline$\geq 75 \mathrm{~g} /$ week & 4 & $6.2 \%$ & 0 & $0.0 \%$ & 4 & $3.1 \%$ & \\
\hline Mn food supplements intake $(n, \%)$ & & & & & & & $0.154^{*}$ \\
\hline No & 63 & $96.9 \%$ & 65 & $100.0 \%$ & 128 & $98.5 \%$ & \\
\hline Yes & 2 & $3.1 \%$ & 0 & $0.0 \%$ & 2 & $1.5 \%$ & \\
\hline Nuts $\geq 5 /$ week $(n, \%)$ & & & & & & & $0.456^{*}$ \\
\hline
\end{tabular}


Table 1 (continued)

\begin{tabular}{|c|c|c|c|c|c|c|c|}
\hline \multirow{2}{*}{$\begin{array}{l}\text { Characteristics } \\
\text { No }\end{array}$} & \multicolumn{2}{|c|}{$\begin{array}{l}\operatorname{ME}(>1.5 \mathrm{~km}) \\
N=65\end{array}$} & \multicolumn{2}{|c|}{$\begin{array}{l}\mathrm{HE}(\leq 1.5 \mathrm{~km}) \\
N=65\end{array}$} & \multicolumn{2}{|c|}{ Total $N=130$} & \multirow[t]{2}{*}{$p$-value } \\
\hline & 57 & $87.7 \%$ & 54 & $83.1 \%$ & 111 & $85.4 \%$ & \\
\hline Yes & 8 & $12.3 \%$ & 11 & $16.9 \%$ & 19 & $14.6 \%$ & \\
\hline Tea $\geq 5 /$ week $(n, \%)$ & & & & & & & 0.019* \\
\hline No & 59 & $90.8 \%$ & 49 & $75.4 \%$ & 108 & $83.1 \%$ & \\
\hline Yes & 6 & $9.2 \%$ & 16 & $24.6 \%$ & 22 & $16.9 \%$ & \\
\hline Fish as tunas or salmon $\geq 3 /$ week $(n, \%)$ & & & & & & & $0.784 *$ \\
\hline No & 58 & $89.2 \%$ & 57 & $87.7 \%$ & 115 & $88.5 \%$ & \\
\hline Yes & 7 & $10.8 \%$ & 8 & $12.3 \%$ & 15 & $11.5 \%$ & \\
\hline
\end{tabular}

with higher concentrations of $\mathrm{Fe}$ and $\mathrm{Pb}$ for males $(492,650 \mu \mathrm{g} / \mathrm{L}$ vs. $466,302 \mu \mathrm{g} / \mathrm{L}$ and $11.40 \mu \mathrm{g} / \mathrm{L}$ vs. $8.49 \mu \mathrm{g} / \mathrm{L}$, respectively), and higher levels of $\mathrm{Cu}$ in females $(824.5 \mu \mathrm{g} / \mathrm{L}$ vs. $716.4 \mu \mathrm{g} / \mathrm{L})$. Regarding to long-term biomarkers, significant sex differences were shown for $\mathrm{Mn}(p=0.008), \mathrm{Cu}(p=0.021), \mathrm{Zn}$ $(p=0.009), \mathrm{Cd}(p=0.020)$ and $\mathrm{Pb}(p=0.007)$ in scalp hair, with higher concentrations for all metals except $\mathrm{Cu}$ in males $(10,639 \mathrm{ng} / \mathrm{g}$ vs. $8450 \mathrm{ng} / \mathrm{g})$, while no significant differences for any metal in the case of fingernails were found. The possible influence of nail varnish on the metal levels was not considered, since only four female volunteers had polished fingernails. In addition, according to the research of Ceballos et al. (2021), the internal levels of metal(loid)s measured in nail technicians' toenails were comparable to those reported in other studies in females, except for antimony, arsenic, chromium, mercury, and nickel.

Figures 2, 3 and 4 show the levels of the selected metal(loid)s in the studied short- and long-term indicators, according to the degree of exposure (highly vs. moderately exposed). In terms of exposure, significant differences of medians were only observed for As in whole blood $(p=0.002), \mathrm{Mn}$ and $\mathrm{Cu}$ in scalp hair ( $p=0.008$ and 0.001 , respectively) and $\mathrm{Mn}$ and $\mathrm{Pb}$ in fingernails $(p<0.001$ and 0.025 , respectively), all concentrations being higher for the highly exposed group with the exception of $\mathrm{Cu}$ in scalp hair. For filters, the most exposed population showed significantly higher concentrations for all the Mn fractions analysed $\left(\mathrm{PM}_{10-2.5}\right.$ and $\mathrm{PM}_{2.5}$, both bioaccessible and non-bioaccessible), as observed in Fig. 2. These differences were maintained statistically significant after adjusting for the potential confounders mentioned in Methodology, as shown in Table 4, except for $\mathrm{Cu}$ in scalp hair and $\mathrm{Mn}$ in the non-bioaccessible fine fraction, which lost significance in the multivariate models.

\section{Correlation analysis}

Spearman's correlation coefficients between the concentration of metal(loid)s in each matrix (filters, whole blood, scalp hair and fingernails) and windweighted distance are shown in Table 5.

For short-term markers, PM-bound Mn showed a significant negative correlation for all the analysed fractions with respect to the weighted distance from the most important source, in which those subjects who live closest to the Mn alloy factory (i.e. in the municipality of Maliaño) were more exposed. Table 5 also shows the lack of correlation between $\mathrm{Mn}$ in whole blood and weighted distance $(r=0.055, p=0.563)$. On the other hand, a significant negative correlation of As in whole blood was found with distance $(r=-0.239$, $p=0.011$ ), but as we will see later, it is not possible to confirm that inhalation was the main route of exposure, since its levels in PM filters were below the LOD.

For long-term biomarkers, Mn showed negative correlations with weighted distance, in agreement with that shown in Fig. 4 for both scalp hair and fingernails, respectively. However, this correlation was only statistically significant for fingernails $(r=-0.607, p<0.001)$. A significant negative correlation with distance to 


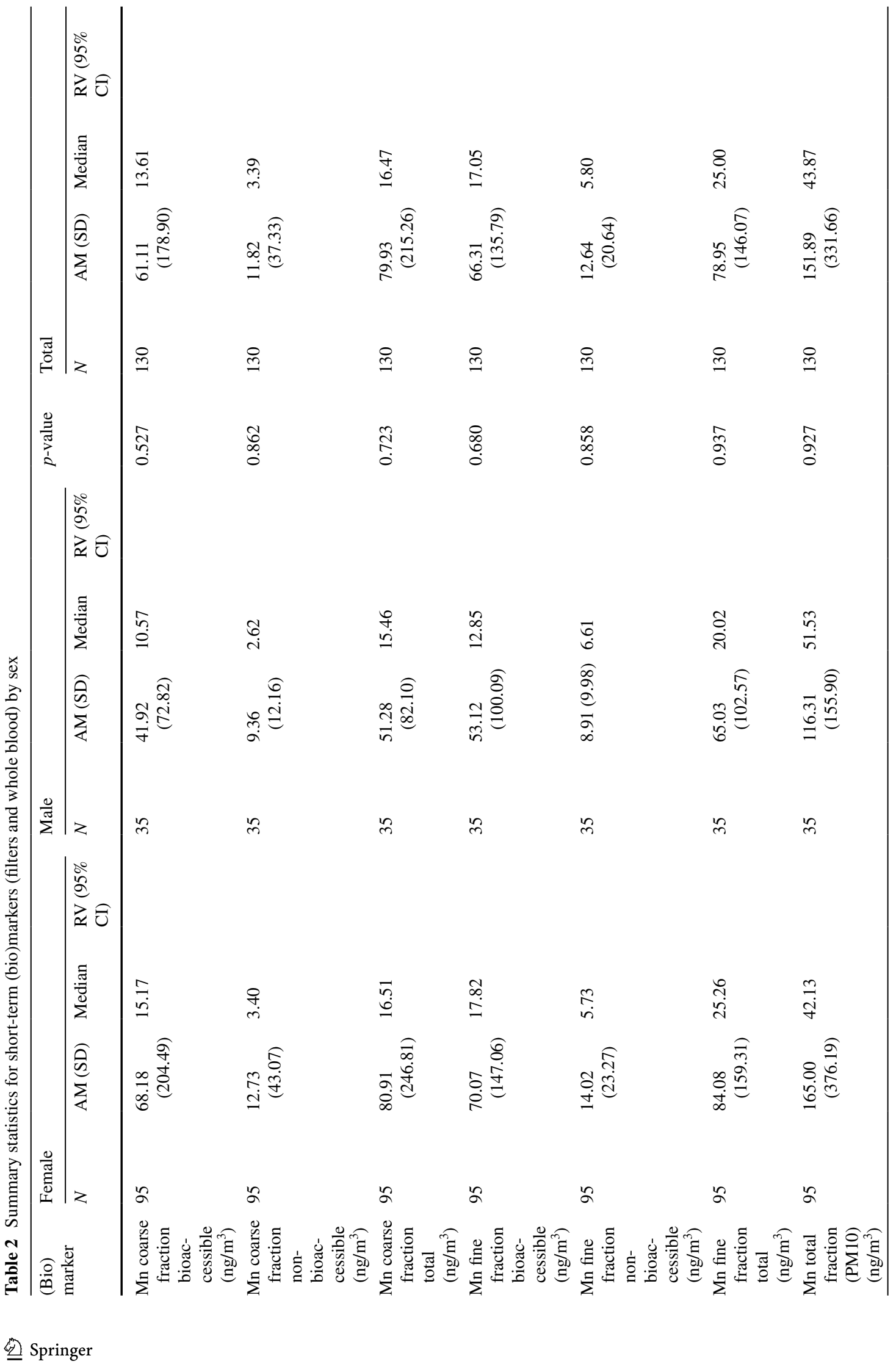




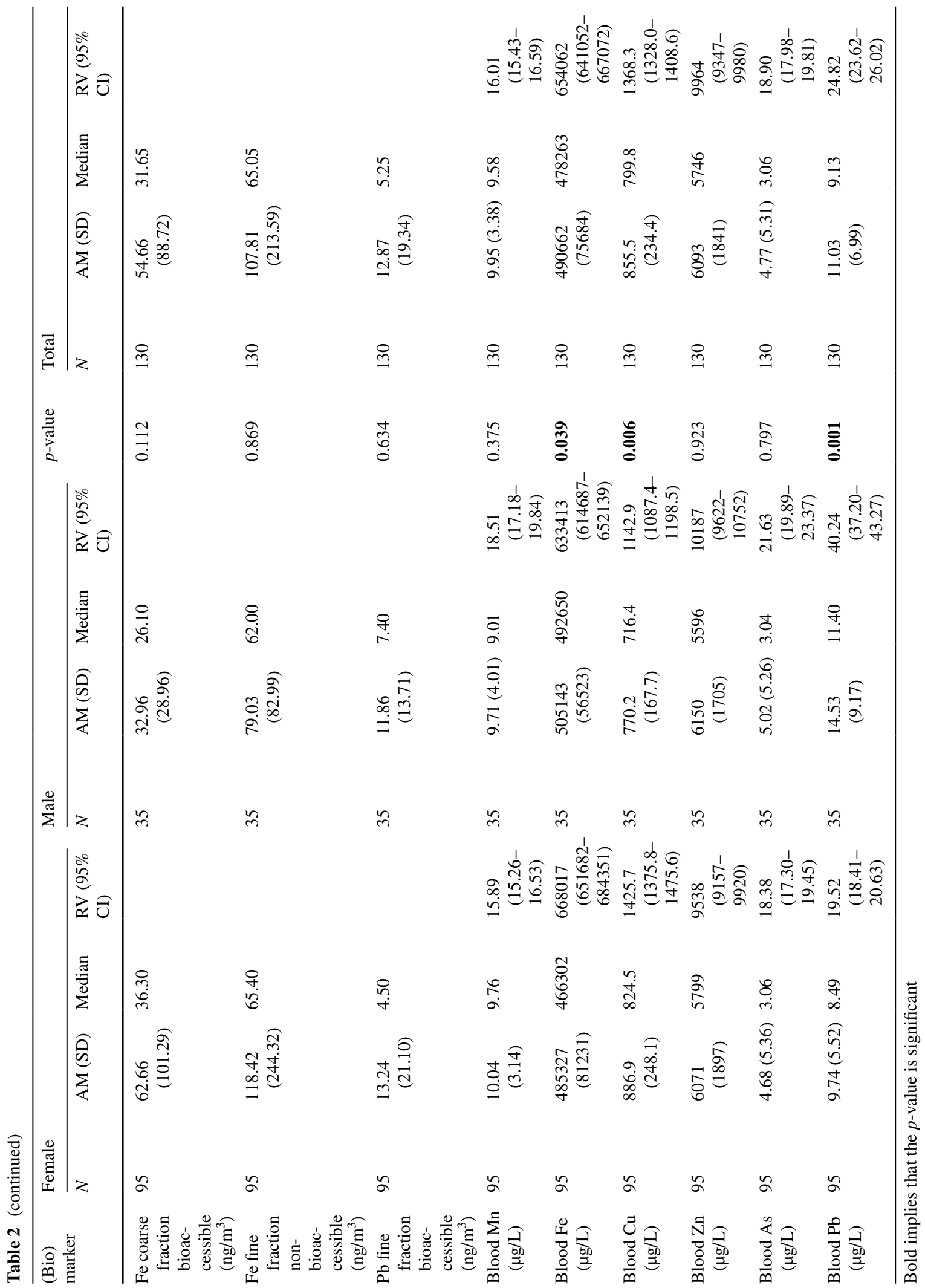


the source was also observed for $\mathrm{Zn}$ in scalp hair ( $r=-0.207, p=0.035$ ), but not in fingernails. Copper and $\mathrm{Fe}$ show no correlation with distance in fingernails, but a positive and significant correlation in scalp hair: Fe $(r=0.269, p=0.006), \mathrm{Cu} \quad(r=0.311, p=0.001)$. With respect to $\mathrm{Pb}$, contradictory results were found: a positive correlation with distance in scalp hair and negative in fingernails, both significant. Negative but no significant correlations were obtained in the bioaccessible fine fraction and whole blood.

The correlations between the metal(loid) concentrations in each matrix and the age of the subjects were also studied (Supplementary Table 3). In whole blood, there was a significant positive correlation of As and $\mathrm{Pb}$ with age $(r=0.367, p<0.001$ and $r=0.451, p<0.001$, respectively), and a significant negative correlation of $\mathrm{Cu}$ with age $(r=-0.239$, $p=0.006$ ), with younger volunteers having higher concentrations, which was also observed in scalp hair $(r=-0.337, p<0.001)$. In fingernails, a significant positive correlation of $\mathrm{Mn}$ concentration with age ( $r=0.315, p=0.001)$ was observed.

Between metal(loid)s correlations in whole blood, scalp hair and fingernails are shown in Supplementary Tables 4-6, respectively. In whole blood, there were significant positive correlations between $\mathrm{Mn} /$ $\mathrm{Fe}(r=0.191, p=0.030), \mathrm{Fe} / \mathrm{Zn}(r=0.283, p=0.001)$, $\mathrm{Cu} / \mathrm{Zn}(r=0.180, p=0.040)$ and $\mathrm{As} / \mathrm{Pb}(r=0.443$, $p<0.001)$. Regarding to scalp hair, all of them were positive: $\mathrm{Mn} / \mathrm{Fe}(r=0.282, p=0.002), \mathrm{Mn} / \mathrm{Cd}$ $(r=0.442, p<0.001), \mathrm{Mn} / \mathrm{Pb}(r=0.348, p<0.001)$, $\mathrm{Fe} / \mathrm{Cd} \quad(r=0.288, \quad p=0.001), \quad \mathrm{Cu} / \mathrm{Cd} \quad(r=0.189$, $p=0.037), \mathrm{Cu} / \mathrm{Pb}(r=0.345, p<0.001)$ and $\mathrm{Cd} / \mathrm{Pb}$ $(r=0.504, p<0.001)$. Finally, the correlations in fingernails between $\mathrm{Mn} / \mathrm{Fe}(r=0.268, p=0.004), \mathrm{Mn} /$ $\mathrm{Pb}(r=0.414, p<0.001), \mathrm{Fe} / \mathrm{Zn}(r=0.340, p<0.001)$, $\mathrm{Fe} / \mathrm{Pb}(r=0.253, p=0.013)$ and $\mathrm{Cu} / \mathrm{Pb}(r=0.211$, $p=0.039$ ) were also significant.

Between matrices correlations for detected metal(loid)s are shown in Supplementary Tables 7 (a-e). Regarding to $\mathrm{Mn}$, no significant correlations between whole blood and any of the Mn fractions analysed in PM nor other biomarkers were observed; however, scalp hair Mn showed significant positive correlations with bioaccessible and total $\mathrm{Mn}$ in both fractions (coarse and fine), and fingernails Mn correlated well with all PM fractions analysed. Significant positive correlations were also observed for Fe between concentrations in scalp hair and fingernails $(r=0.228, p=0.018)$ and between $\mathrm{Pb}$ concentrations in whole blood and scalp hair $(r=0.210, p=0.020)$.

\section{Discussion}

The discussion is first focused on $\mathrm{Mn}$, because the study area is characterised by the presence of a ferromanganese alloy factory as the main source of metal(loid) emissions (Hernández-Pellón \& Fernández-Olmo, 2019; Hernandez-Pellón et al., 2017), and due to the lack of consensus for the choice of a suitable biomarker for $\mathrm{Mn}$, which is further difficulted by its role as a micronutrient (Aschner \& Aschner, 2005; Hassani et al., 2016; Jursa et al., 2018). In addition, according to a previous study, this plant is practically the only source of airborne $\mathrm{Mn}$ in the study area (Otero-Pregigueiro et al., 2018).

In general, Mn levels in the studied markers are higher in the highly exposed group, with the exception of whole blood. This is corroborated when the correlation between Mn levels in these (bio)markers is analysed. Among the studied indicators of the $\mathrm{Mn}$ exposure, the PM-bound Mn concentration showed the highest differences between exposure groups, mainly for the bioaccessible fractions (see Figs. 2, 3, 4). Effect sizes and statistical significance were maintained after adjusting for potential confounders except for the non-bioaccessible fine fraction (see Table 4), highlighting the importance of the inhalation route of exposure to Mn from the ferromanganese industry emissions, in agreement with previous modelling and stationary sampling studies (Hernández-Pellón \& Fernández-Olmo, 2019; Otero-Pregigueiro et al., 2018), with the improvement of accurate 24-h exposure monitoring in which each volunteer carried the personal sampler. Table 5 also confirmed this hypothesis, since the highest correlations between Mn levels and weighted distance were obtained for PM filters, with higher correlation coefficients for the bioaccessible fractions with respect to the non-bioaccessible fractions.

Although the measured Mn levels in biomarkers can result from the three routes of exposure, the results discussed above on PM-bound Mn concentrations and the importance of the bioaccessible fraction can explain the results obtained when scalp hair and fingernails are used. Thus, as shown in Fig. 4, 


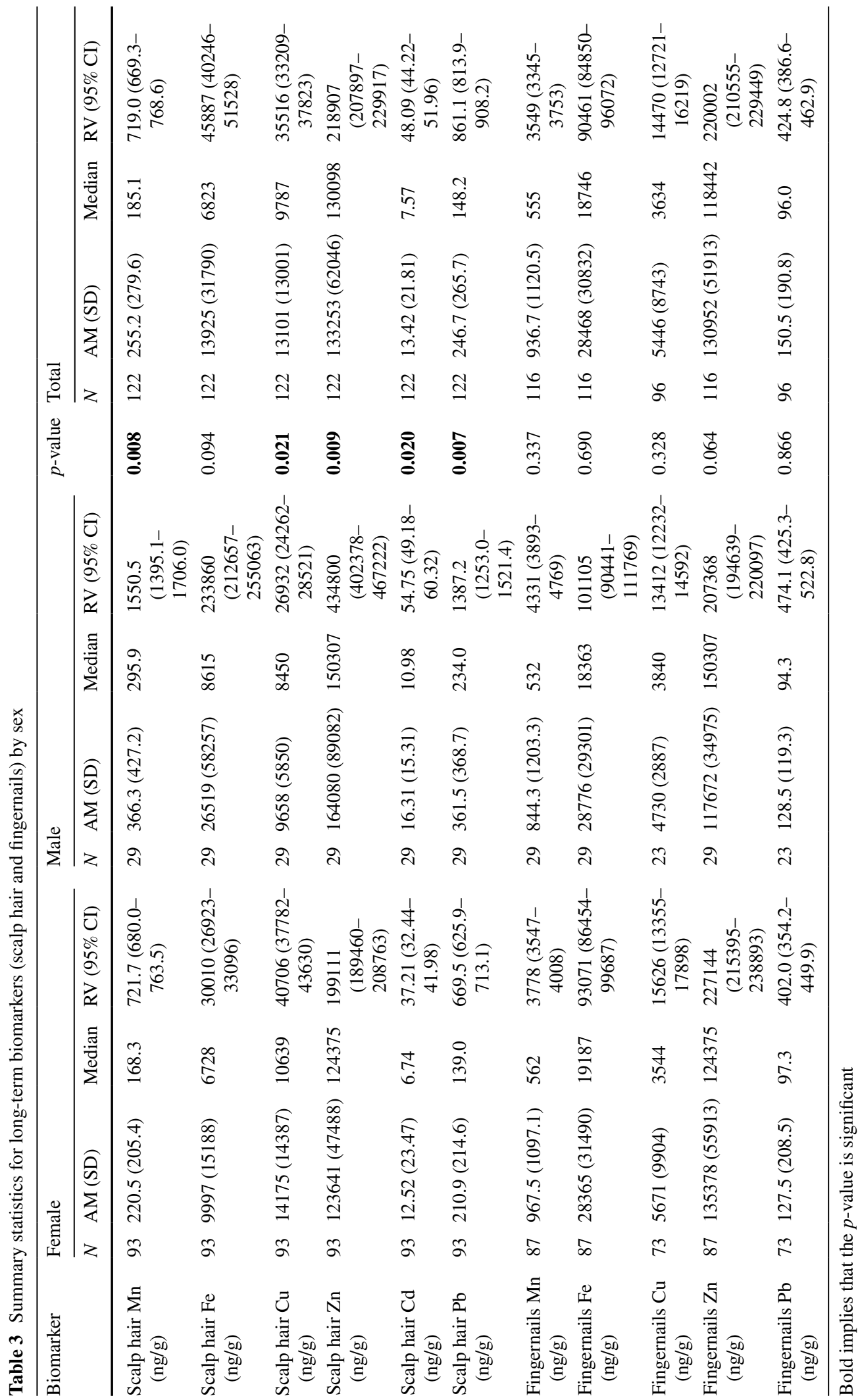


(a)

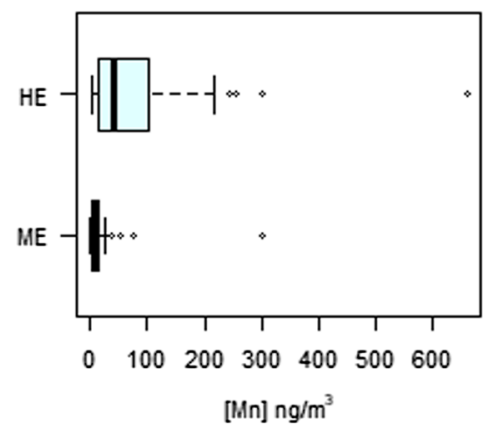

(d)

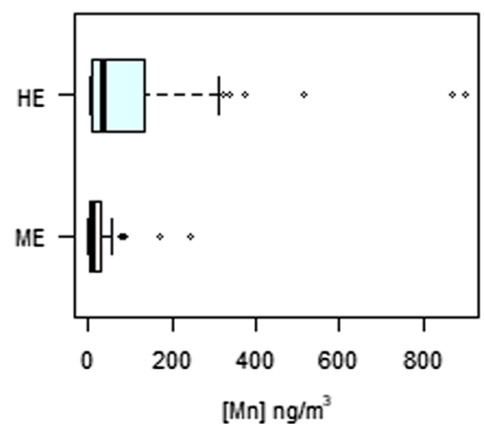

(b)

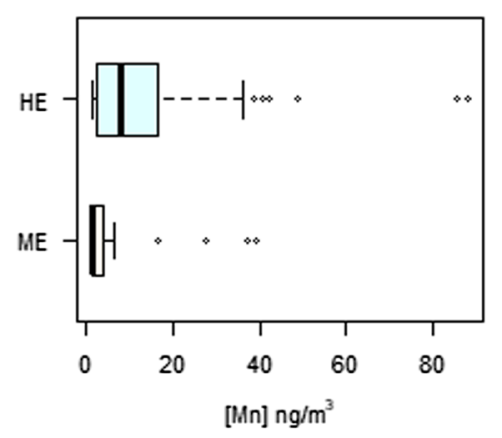

(e)

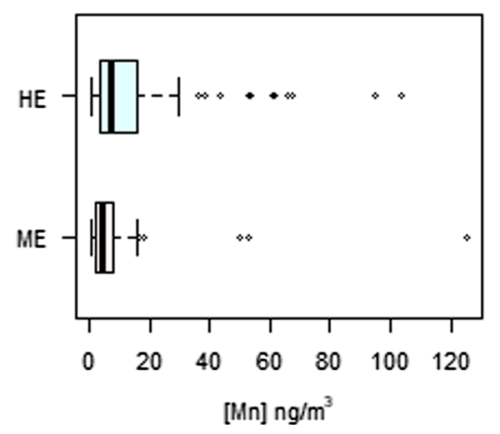

(c)

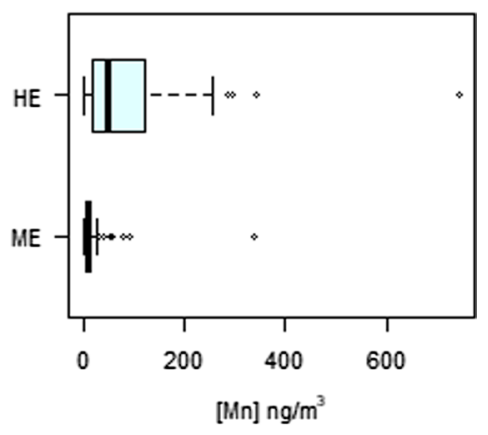

(f)

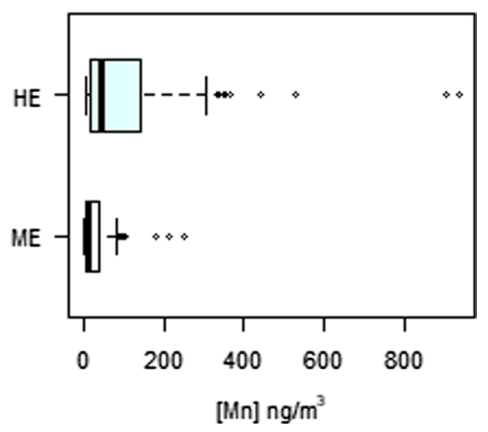

Fig. 2 Levels of $\mathrm{Mn}$ in filters from personal sampling according to the exposure to the main Mn source: moderately exposed (ME) versus highly exposed (HE): (a) bioaccessible,

we can consider scalp hair and mainly fingernails as potential biomarkers of long-term airborne Mn exposure. The most exposed population showed medians of $321.6 \mathrm{ng} / \mathrm{g}$ and $917.9 \mathrm{ng} / \mathrm{g}$ in scalp hair and fingernails, respectively, with these concentrations being notably lower for the less exposed population (132.7 ng/g and $331.3 \mathrm{ng} / \mathrm{g}$, respectively), as evidenced in other studies (Coetzee et al., 2016; Haynes et al., 2015; Levin-Schwartz et al., 2021). These differences are again maintained after adjusting for potential confounders (see Table 4). The appropriateness of these biomarkers is also corroborated by the results of the calculation of between matrices correlations for Mn. We observed positive correlations with bioaccessible and total $\mathrm{Mn}$ in both fractions (coarse and fine) in the case of scalp hair, and with all PM fractions analysed in the case of fingernails.

Our results also suggest that whole blood is not a good biomarker of short-term airborne Mn exposure (see Fig. 3), being unable to differentiate between highly and moderately exposed groups (medians
$\mathrm{PM}_{10-2.5}$; (b) non-bioaccessible, $\mathrm{PM}_{10-2.5}$; (c) total, $\mathrm{PM}_{10-2.5}$; (d) bioaccessible, $\mathrm{PM}_{2.5}$; (e) non-bioaccessible, $\mathrm{PM}_{2.5}$; (f) total, $\mathrm{PM}_{2.5}$

$9.16 \mu \mathrm{g} / \mathrm{L}$ vs. $9.18 \mu \mathrm{g} / \mathrm{L}, p=0.865)$, even after adjusting for potential confounders. This is in agreement with previous studies reporting that Mn levels are tightly regulated in this matrix, with excess being quickly eliminated by the liver and excreted in bile and urine (Gurol et al., 2022). The correlation analysis also confirmed that whole blood cannot be used as biomarker of environmental exposure to Mn with epidemiological purposes, as it did not show significant correlations with any of the Mn fractions analysed in PM, nor with other biomarkers, nor with distance to the source.

With respect to $\mathrm{Pb}, \mathrm{Zn}$ and $\mathrm{Fe}$, their presence in the study area was also mainly attributed to the ferroalloy factory (Hernández-Pellón \& FernándezOlmo, 2019). This was supported by the significant positive correlations between $\mathrm{Mn}, \mathrm{Pb}, \mathrm{Zn}$ and $\mathrm{Fe}$ found in fingernails. However, other nearby emission sources such as a steel plant for $\mathrm{Pb}, \mathrm{Zn}$ and $\mathrm{Fe}$ and non-exhaust road traffic for $\mathrm{Zn}$ and $\mathrm{Fe}$ cannot be ruled out. Regarding to $\mathrm{Pb}$, blood has been considered as 
(a)

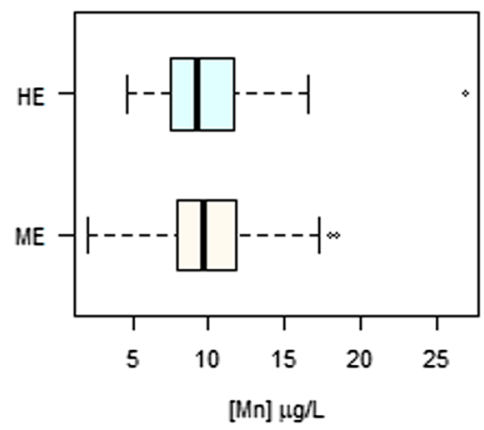

(d)

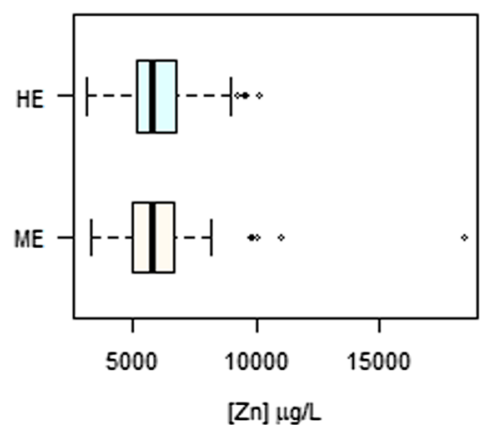

(b)

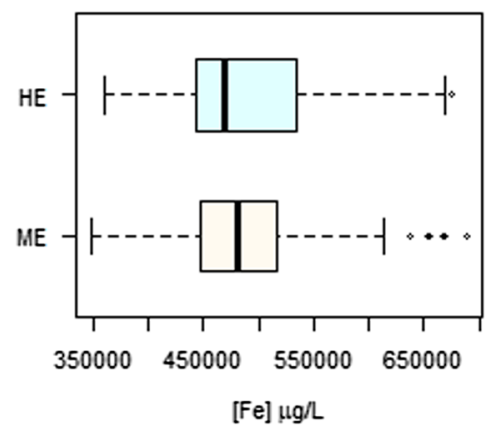

(e)

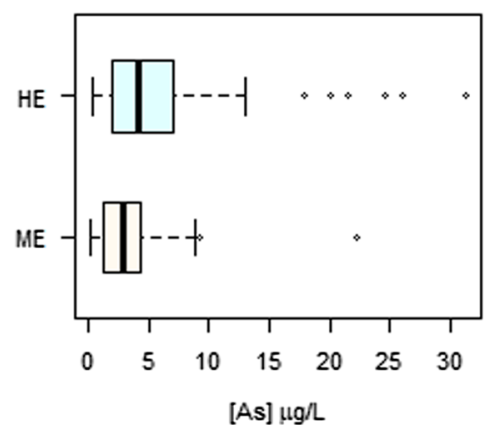

(c)

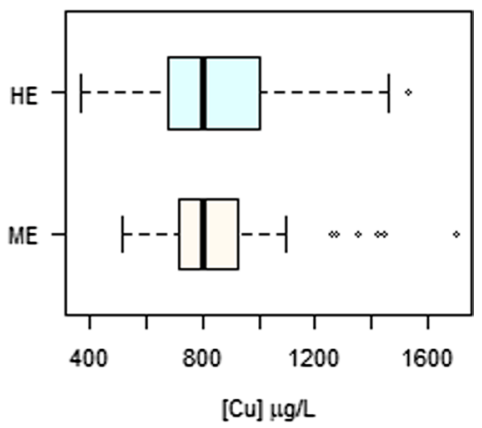

(f)

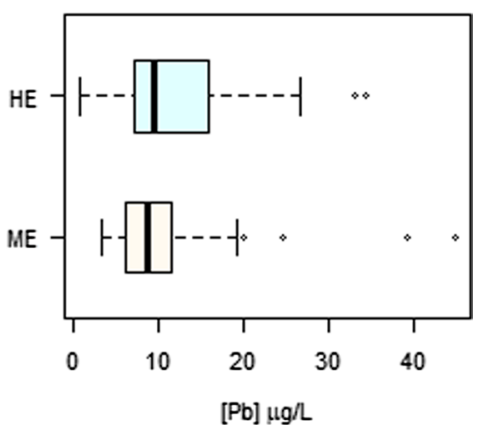

Fig. 3 Levels of metal(loid)s in whole blood as short-term biomarker according to the exposure to the main Mn source: moderately exposed (ME) versus highly exposed (HE): (a) $\mathrm{Mn}$; (b) $\mathrm{Fe}$; (c) $\mathrm{Cu}$; (d) $\mathrm{Zn}$; (e) $\mathrm{As}$; (f) $\mathrm{Pb}$

a reliable biomarker of exposure (Barbosa et al., 2005). However, although the levels of $\mathrm{Pb}$ in whole blood were higher in the highly exposed group (see Fig. 3), the difference was not statistically significant $(p=0.106)$. It should be noted that the steel plant is located only $3.5 \mathrm{~km} \mathrm{~N}$ from the ferroalloy factory, so its emissions can affect both the highly and the moderately exposed groups. Moreover, contradictory results were found for long-term biomarkers: a positive correlation with distance in scalp hair and negative in fingernails, both significant (see Table 5). Thus, while Fig. 4 depicts significant differences between groups in fingernails, with higher levels in the highly exposed group (103.3 vs. $82.8 \mathrm{ng} / \mathrm{g}$, $p=0.025$ ), but contrary to our hypothesis, $\mathrm{Pb}$ concentration in scalp hair was slightly higher in the moderately exposed group $(p=0.088)$. Although it is well known that blood and nails can be effective biomarkers of $\mathrm{Pb}$ exposure (Barbosa et al., 2005; Olympio et al., 2020), the contradictory results shown here for the three biomarkers studied need further research to elucidate (i) the suitability of these biomarkers to account for the exposure to airborne $\mathrm{Pb}$, and (ii) the contribution of local emission sources other than ferroalloy smelting.

This study also confirmed that the actual levels of whole blood $\mathrm{Pb}$ are much lower than those of previous decades, even in industrial areas like Santander Bay, due to the strict regulations given worldwide. For example, RVs of 70 and $90 \mu \mathrm{g} / \mathrm{L}$ was derived by the Human Biomonitoring (HBM) Commission for women and men, respectively, in the period 1997-1999 (Schulz et al., 2011), much higher than the RV of $24.82 \mu \mathrm{g} / \mathrm{L}$ measured in this work. It also agrees with the report produced by the US Department of Health and Human Services (2018), with a $\mathrm{P}_{95}$ of $23.9 \mu \mathrm{g} / \mathrm{L}$ in $2015 / 2016$. Other recent studies showed similar levels, such as those shown by Saravanabhavan et al. (2017) in a Canadian biomonitoring study, with a $\mathrm{P}_{95}$ of $33 \mu \mathrm{g} / \mathrm{L}$, or by Ferreira et al. (2019) in an unexposed population in Brazil $\left(\mathrm{P}_{95}=22.5 \mu \mathrm{g} / \mathrm{L}\right)$. In Spain, a former national 
(a)

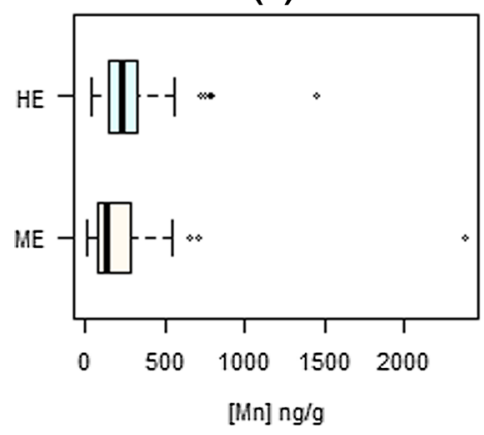

(d)

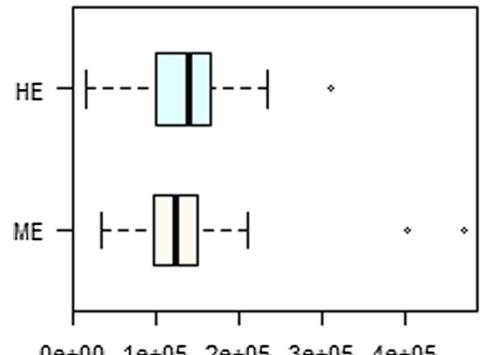

$0 e \div 00 \quad 1 e \div 05 \quad 2 e \div 05 \quad 3 e \div 05 \quad 4 e \div 05$

$[\mathrm{Zn}] \mathrm{ng} / \mathrm{g}$

(g)

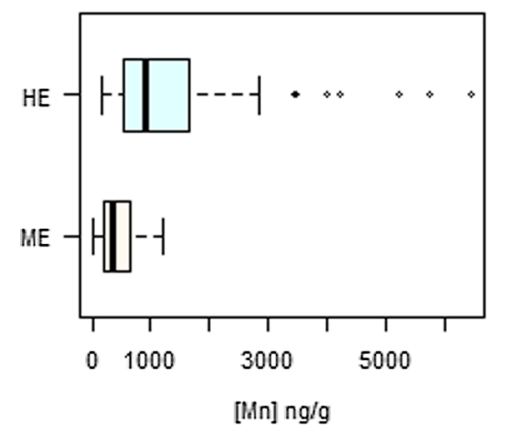

(j)

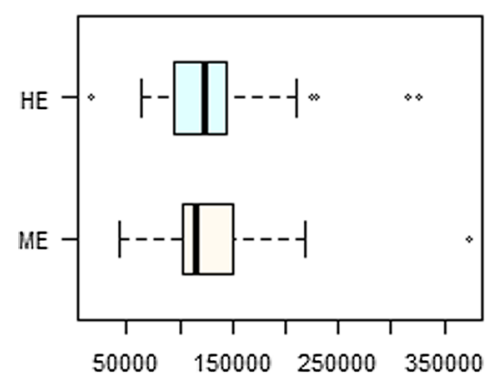

$[\mathrm{Zn}] \mathrm{ng} / \mathrm{g}$ (b)

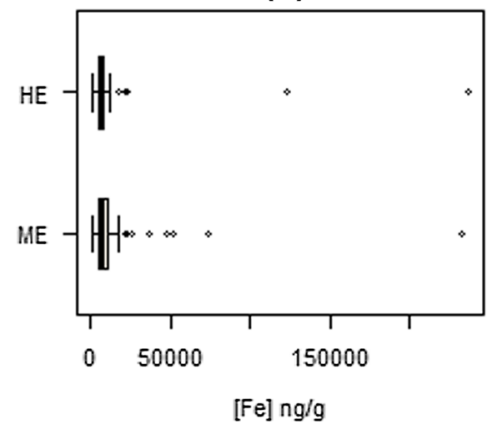

(e)

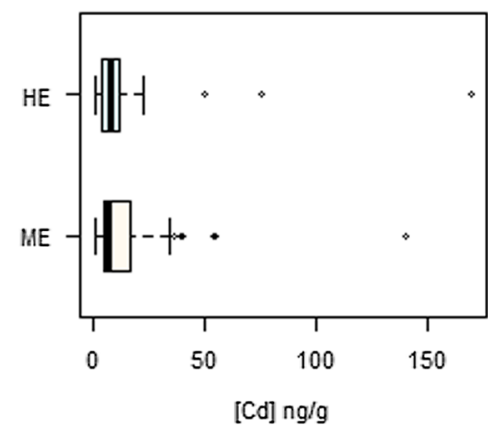

(h)

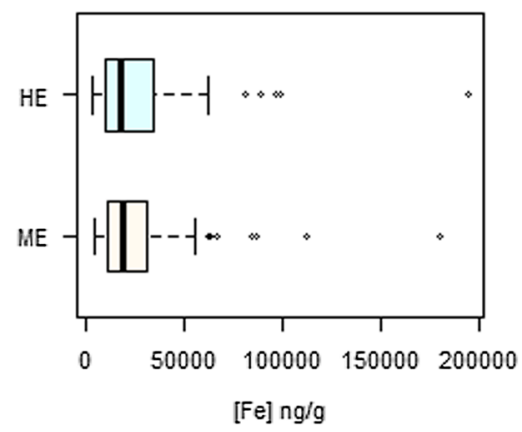

(k)

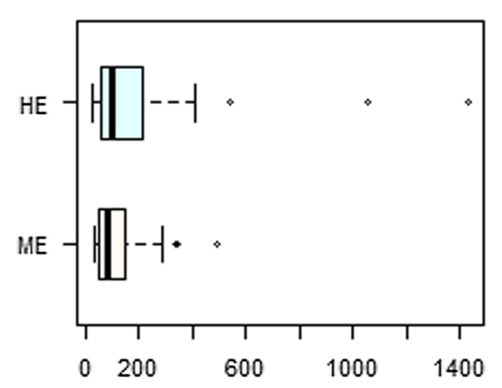

$[\mathrm{Pb}] \mathrm{ng} / \mathrm{g}$ (c)

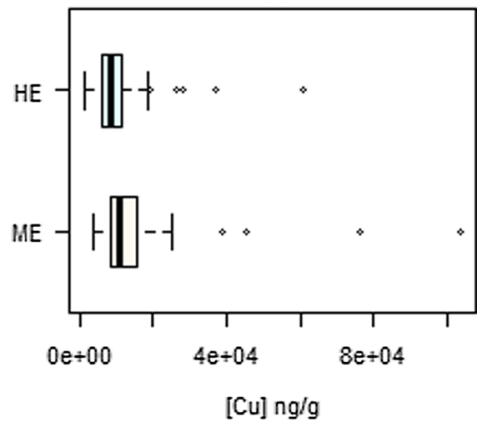

(f)

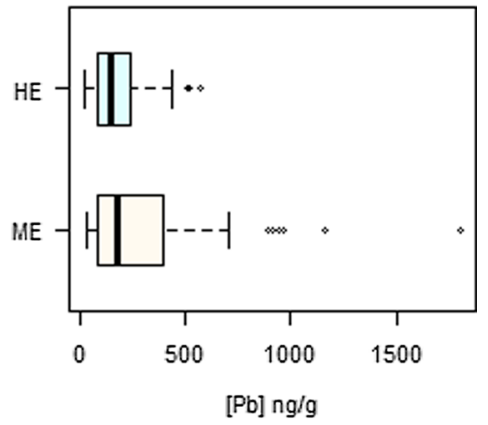

(i)

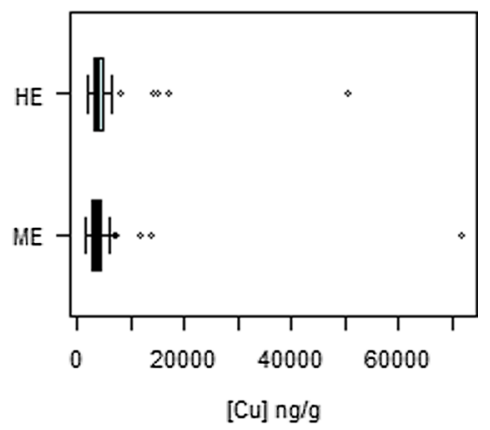


4Fig. 4 Levels of metals in long-term biomarkers according to the degree of exposure to the main Mn source: moderately exposed (ME) versus highly exposed (HE): (a) scalp hair Mn; (b) scalp hair Fe; (c) scalp hair $\mathrm{Cu}$; (d) scalp hair Zn; (e) scalp hair $\mathrm{Cd}$; (f) scalp hair $\mathrm{Pb}$; (g) fingernails $\mathrm{Mn}$; (h) fingernails $\mathrm{Fe}$; (i) fingernails $\mathrm{Cu}$; (j) fingernails $\mathrm{Zn}$; k) fingernails $\mathrm{Pb}$

biomonitoring study carried out between 2009 and 2010 (BIOAMBIENT) reported a $\mathrm{P}_{95}$ value of $56.8 \mu \mathrm{g} / \mathrm{L}$ (Cañas et al., 2014), evidencing this progressive decrease of $\mathrm{Pb}$ levels in blood.

With respect to $\mathrm{Zn}$ and $\mathrm{Fe}$, a significant negative correlation with distance to the source was observed for $\mathrm{Zn}$ in scalp hair $(r=-0.207, p=0.035)$, but not in fingernails $(r=-0.032, p=0.754)$, while no correlation with distance in fingernails and even positive significant correlation in scalp hair was found for $\mathrm{Fe}$ $(r=0.269, p=0.006)$. Again, the presence of other sources of these metals in the area makes it difficult to interpret these results. In addition, $\mathrm{Zn}$ and $\mathrm{Fe}$ are essential trace elements that can enter into the body by other routes.

Copper shows no significant differences as a function of exposure in whole blood and fingernails, although it does in scalp hair, but losing significance after adjusting for the selected confounders, mainly attributed to age differences (older people in the highly exposed group, as shown in Table 1, and negative correlation between scalp hair $\mathrm{Cu}$ and age, as shown in Supplementary Table 3). In any case, higher scalp hair $\mathrm{Cu}$ levels are measured in the moderately exposed population, in agreement with a positive significant correlation with distance $(r=0.311$, $p=0.001$ ), concluding that the origin of this metal is not due to the ferroalloys plant. According to the literature, airborne $\mathrm{Cu}$ originates mainly from nonexhaust emissions due to brake wear (Amato et al., 2010; Bäckström et al., 2003; Johansson et al., 2009). These results are consistent, as road traffic is similar or even higher in Santander area, where most of the moderately exposed group lives.

Finally, As exhibited important differences in whole blood (see Fig. 3), with the most exposed population showing statistically significant higher levels (4.24 $\mu \mathrm{g} / \mathrm{L}$ vs. $2.81 \mu \mathrm{g} / \mathrm{L}, p=0.002)$. This agrees with a significant negative correlation found with the distance to the factory $(r=-0.239, p=0.011)$. However, it seems that it does not bioaccumulate long-term in the body, remaining below the LOD in both scalp hair and fingernails. The origin of As in this area needs further investigation, since although it was measured in previous studies both in $\mathrm{PM}_{10}$ collected by stationary samplers (Hernández-Pellón \& Fernández-Olmo, 2019) and in soil (Boente et al., 2020) near the ferromanganese plant, the levels of As in the bioaccessible and non-bioaccessible fractions of the personal filters collected in the present study were below the LOD, so other sources and routes of exposure are not ruled out.

The differences with respect to the sex of the participants are in line with those reported in previous studies (Bocca et al., 2011; Coelho et al., 2014; Saravanabhavan et al., 2017; Stojsavljević et al., 2019). Coelho et al. (2014) reported higher levels of Mn in toenails in females, in agreement with our results using fingernails. The higher whole blood $\mathrm{Pb}$ concentrations found in males are in accordance with those reported by Batáriová et al. (2006), Coelho et al. (2014), Schulz et al. (2011), Stojsavljević et al. (2019) and Zhang et al. (2015). Moreover, the higher whole blood $\mathrm{Cu}$ levels in females are in agreement with Bocca et al. (2011) and Zeng et al. (2019), and may be due to the fact that estrogen-induced ceruloplasmin synthesis in the liver, can lead to increased blood $\mathrm{Cu}$ levels in females (Prasad et al., 2014). On the other hand, no significant sex differences in whole blood $\mathrm{Mn}$ and As levels have been found, supported by Freire et al. (2015), Haynes et al. (2010), Nisse et al. (2017), Stojsavljević et al. (2019) and Zeng et al. (2019). However, contrary to us, Zeng et al. (2019) reported higher levels of $\mathrm{Zn}, \mathrm{Fe}$ and $\mathrm{As}$ in the whole blood of males.

For males, significant higher levels of Mn in scalp hair were also observed, which is in agreement with Viana et al. (2014), although the significance they reported is limited. Nonetheless, other literature studies reported no significant differences in hair Mn levels according to sex (Haynes et al., 2010; MenezesFilho et al., 2009; Riojas-Rodríguez et al., 2010).

The biomonitoring levels obtained in this study were also compared with the available literature. In the case of whole blood, our biomonitoring values were within the range or slightly below those reported in the literature with the exception of As; for this metal(loid), some outliers were measured, corresponding to participants living in the vicinity of the main source of metals in Maliaño. It is unusual to find As values in whole blood higher than $15 \mu \mathrm{g} / \mathrm{L}$, 


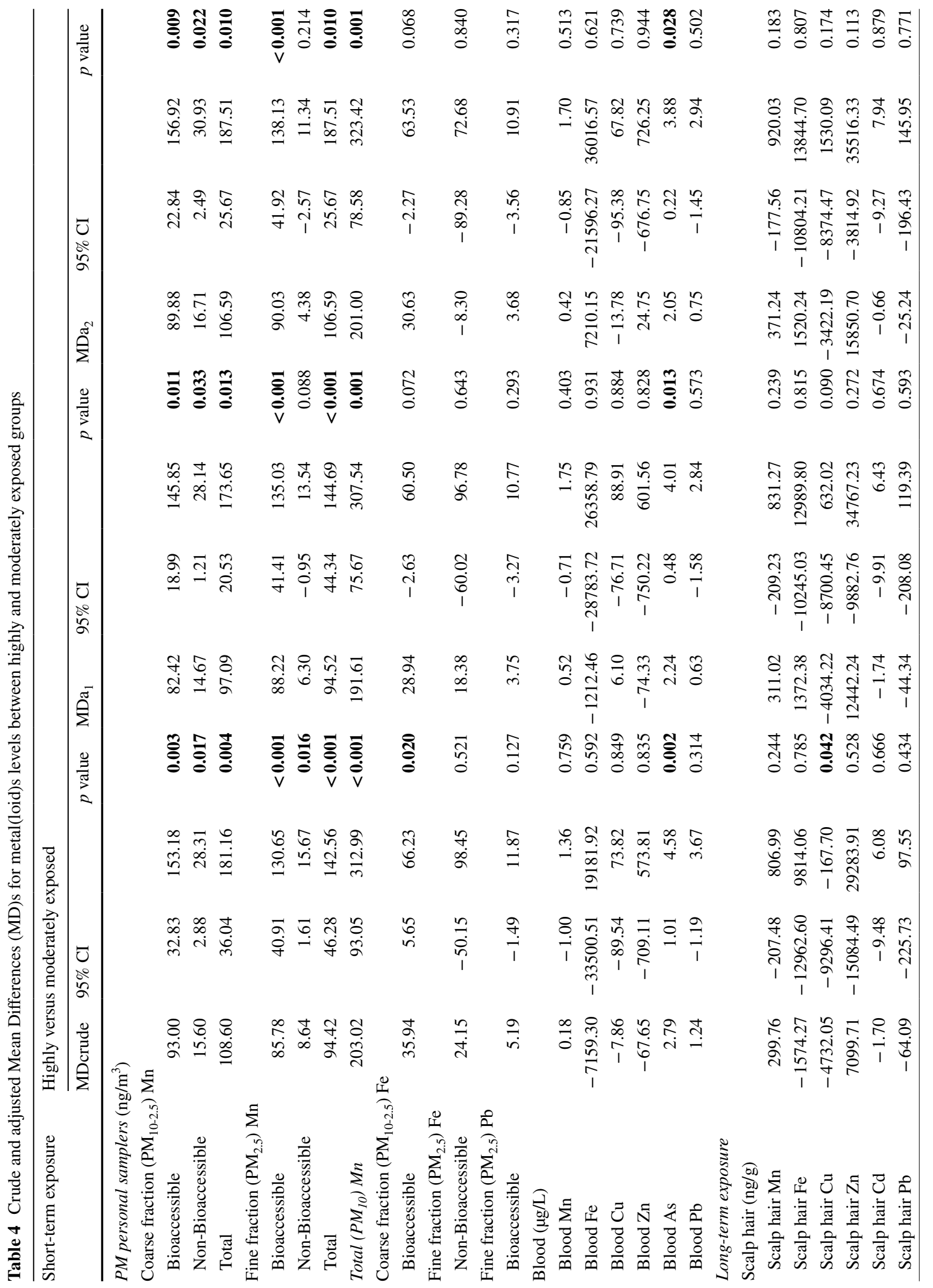


Table 5 Spearman's correlation coefficients between concentrations of all employed (bio)markers and wind-weighted distance; markers are shown in two groups according to the distance weighting methods used: short-term and long-term

\begin{tabular}{|c|c|c|}
\hline & $r$ & $p$-value \\
\hline \multicolumn{3}{|l|}{ Short-term (bio)markers } \\
\hline Mn coarse fraction bioaccessible $\left(\mathrm{ng} / \mathrm{m}^{3}\right)$ & -0.609 & $<0.001$ \\
\hline $\begin{array}{l}\text { Mn coarse fraction non-bioaccessible (ng/ } \\
\mathrm{m}^{3} \text { ) }\end{array}$ & -0.44 & $<0.001$ \\
\hline Mn coarse fraction total $\left(\mathrm{ng} / \mathrm{m}^{3}\right)$ & -0.612 & $<0.001$ \\
\hline Mn fine fraction bioaccessible $\left(\mathrm{ng} / \mathrm{m}^{3}\right)$ & -0.449 & $<0.001$ \\
\hline $\begin{array}{l}\text { Mn fine fraction non-bioaccessible (ng/ } \\
\left.\mathrm{m}^{3}\right)\end{array}$ & -0.319 & 0.001 \\
\hline Mn fine fraction total $\left(\mathrm{ng} / \mathrm{m}^{3}\right)$ & -0.439 & $<0.001$ \\
\hline Mn total $\left(\mathrm{PM}_{10}\right)\left(\mathrm{ng} / \mathrm{m}^{3}\right)$ & -0.549 & $<0.001$ \\
\hline $\mathrm{Fe}$ coarse fraction bioaccessible $\left(\mathrm{ng} / \mathrm{m}^{3}\right)$ & -0.343 & $<0.001$ \\
\hline Fe fine fraction non-bioaccessible $\left(\mathrm{ng} / \mathrm{m}^{3}\right)$ & -0.150 & 0.114 \\
\hline $\mathrm{Pb}$ fine fraction bioaccessible $\left(\mathrm{ng} / \mathrm{m}^{3}\right)$ & -0.179 & 0.057 \\
\hline Whole blood Mn $(\mu \mathrm{g} / \mathrm{L})$ & 0.055 & 0.563 \\
\hline Whole blood Fe ( $\mu \mathrm{g} / \mathrm{L})$ & 0.065 & 0.495 \\
\hline Whole blood $\mathrm{Cu}(\mu \mathrm{g} / \mathrm{L})$ & 0.152 & 0.109 \\
\hline Whole blood $\mathrm{Zn}(\mu \mathrm{g} / \mathrm{L})$ & 0.028 & 0.766 \\
\hline Whole blood As ( $\mu \mathrm{g} / \mathrm{L})$ & -0.239 & 0.011 \\
\hline Whole blood $\mathrm{Pb}(\mu \mathrm{g} / \mathrm{L})$ & -0.063 & 0.506 \\
\hline \multicolumn{3}{|l|}{ Long-term biomarkers } \\
\hline Scalp hair Mn (ng/g) & -0.104 & 0.291 \\
\hline Scalp hair Fe (ng/g) & 0.269 & 0.006 \\
\hline Scalp hair $\mathrm{Cu}(\mathrm{ng} / \mathrm{g})$ & 0.311 & 0.001 \\
\hline Scalp hair Zn (ng/g) & -0.207 & 0.035 \\
\hline Scalp hair Cd (ng/g) & 0.151 & 0.127 \\
\hline Scalp hair $\mathrm{Pb}(\mathrm{ng} / \mathrm{g})$ & 0.300 & 0.002 \\
\hline Fingernails Mn (ng/g) & -0.607 & $<0.001$ \\
\hline Fingernails $\mathrm{Fe}$ (ng/g) & 0.041 & 0.682 \\
\hline Fingernails $\mathrm{Cu}$ (ng/g) & -0.039 & 0.725 \\
\hline Fingernails Zn (ng/g) & -0.032 & 0.754 \\
\hline Fingernails $\mathrm{Pb}$ (ng/g) & -0.344 & $<\mathbf{0 . 0 0 1}$ \\
\hline
\end{tabular}

Bold implies that the $p$-value is significant

although there have been previous studies reporting As levels similar to our outliers, such as those of Tratnik et al. (2019) (maximum As in women of $28.9 \mu \mathrm{g} / \mathrm{L}$ and in men of $22.4 \mu \mathrm{g} / \mathrm{L}$ ), Freire et al. (2015), (maximum As in women of $26.28 \mu \mathrm{g} / \mathrm{L}$ and in men of $30.75 \mu \mathrm{g} / \mathrm{L}$ ), Henríquez-Hernández et al. (2018) (maximum As of $29.12 \mu \mathrm{g} / \mathrm{L}$ in population aged 20-40 years in the Canary Islands (Spain)), and Kim et al. (2017) in South Korea (maximum As of $59.8 \mu \mathrm{g} / \mathrm{L}$ in women and 53.1 $\mu \mathrm{g} / \mathrm{L}$ in men). 
In the case of $\mathrm{Mn}$, the median $(9.76 \mu \mathrm{g} / \mathrm{L})$ was slightly higher than that found in the USA from the Fourth National Report on Human Exposure to Environmental Chemicals, $9.52 \mu \mathrm{g} / \mathrm{L}$ in 2015/2016 from a sample of 4987 participants (US Department of Health \& Human Services, 2018). The highest values of $\mathrm{Mn}$ in whole blood corresponded to participants living near the manganese alloy plant, but their maximum $(26.76 \mu \mathrm{g} / \mathrm{L})$ was clearly below some values reported near industrial sources of $\mathrm{Mn}$ : for example, Santos-Burgoa et al. (2001) reported a maximum of $88 \mu \mathrm{g} / \mathrm{L}$ near Mn ore mines in Mexico.

With respect to scalp hair, our values were in general well below those documented, except for $\mathrm{Zn}$ and $\mathrm{Cu}$, which were within the range of other studies. This may be due to the fact that our cleaning protocol is much more thorough than most protocols used by other authors, leading to a complete removal of exogenous contamination of scalp hair by trace metals. The influence of pre-treatment steps on the levels of metals in hair has been discussed in the literature (Eastman et al., 2013). These differences were also observed in the case of fingernails, with the peculiarity that the literature studies available to compare our range of values were more limited.

Our ranges of concentrations in scalp hair and fingernails were in the same order of magnitude as those obtained by Butler et al. (2019), who used the same cleaning protocol previously reported by Eastman et al. (2013). For example, for $\mathrm{Mn}, \mathrm{Cu}$ and $\mathrm{Pb}$ in scalp hair, they obtained medians of $0.08,9.57$ and $0.17 \mu \mathrm{g} / \mathrm{g}$, respectively, compared to the medians obtained in this study of $0.19,9.79$ and $0.15 \mu \mathrm{g} / \mathrm{g}$, respectively. However, studies in which a less thorough cleaning protocol was used showed much higher Mn levels in hair (e.g. 6.9-31.3 $\mu \mathrm{g} / \mathrm{g}$ in MenezesFilho et al. (2009), $12 \mu \mathrm{g} / \mathrm{g}$ in Mohmand et al. (2015), and $9.7 \mu \mathrm{g} / \mathrm{g}$ for males and $4.4 \mu \mathrm{g} / \mathrm{g}$ for females in Viana et al. (2014)). For nails, something similar occurred, as Butler et al. (2019) obtained medians for $\mathrm{Mn}, \mathrm{Cu}$ and $\mathrm{Pb}$ of $0.19,2.66$ and $0.1 \mu \mathrm{g} / \mathrm{g}$, respectively, while for the same metals our medians were $0.56,3.63$ and $0.1 \mu \mathrm{g} / \mathrm{g}$, respectively.

\section{Conclusions}

Among the studied indicators of Mn exposure, PM-bound Mn concentrations showed the largest differences between the highly exposed and moderately exposed, highlighting the importance of the inhalation route of exposure to $\mathrm{Mn}$ from emissions of the ferromanganese industry. The higher fingernails Mn levels of people living near the Mn source and the significant positive correlations between fingernails Mn and all PM fractions (bioaccessible/non-bioaccessible coarse and fine) confirm it as the best biomarker of long-term exposure to $\mathrm{Mn}$, the main pollutant in Santander Bay according to WHO guidelines.

With respect to $\mathrm{Pb}, \mathrm{Zn}$ and $\mathrm{Fe}$, their presence in the study area was also mainly attributed to the ferroalloy factory; however, other nearby emission sources cannot be ruled out, such as a steel plant for $\mathrm{Pb}, \mathrm{Zn}$ and $\mathrm{Fe}$ and non-exhaust road traffic for $\mathrm{Zn}$ and Fe; moreover, $\mathrm{Zn}$ and $\mathrm{Fe}$ are essential trace elements that can enter the organism by other routes. The contradictory results shown here for the three studied biomarkers, mainly for $\mathrm{Pb}$, indicate the difficulties in interpreting the results when different environmental metal(loid) sources and routes of exposure to them may occur. Finally, this study also confirmed that current whole blood $\mathrm{Pb}$ levels, even in an urban-industrial mixed area, are much lower than in previous decades.

Acknowledgements We thank the computational assistance provided by Victoria Gallardo. We also thank Emma Campillo (Lund University) for checking the English language and Bruno Carral for his support in the calculation of the windweighted distance.

Author contribution B.M.: Investigation, Writing-Original draft preparation, Formal analysis; L.R.-A.: Investigation (samples collection); A.E.: Investigation; M.S.: Supervision, Funding acquisition, Formal analysis; I.F.-O.: Conceptualisation, Methodology, Reviewing and Editing, Supervision, Funding acquisition.

Funding This work was supported by the Spanish Ministry of Science and Innovation (Project CTM2017-82636-R, funded by MCIN/AEI/10.13039/501100011033 and "ERDF A way of making Europe"). Bohdana Markiv also thanks the MICIU for her predoctoral contract (PRE2018-085152, financed together by MCIN/AEI/10.13039/501100011033 and "ESF Investing in your future"). Open Access funding provided thanks to the CRUE-CSIC agreement with Springer Nature.

\section{Declarations}

Conflict of interests The authors have not disclosed any competing interests.

Open Access This article is licensed under a Creative Commons Attribution 4.0 International License, which permits 
use, sharing, adaptation, distribution and reproduction in any medium or format, as long as you give appropriate credit to the original author(s) and the source, provide a link to the Creative Commons licence, and indicate if changes were made. The images or other third party material in this article are included in the article's Creative Commons licence, unless indicated otherwise in a credit line to the material. If material is not included in the article's Creative Commons licence and your intended use is not permitted by statutory regulation or exceeds the permitted use, you will need to obtain permission directly from the copyright holder. To view a copy of this licence, visit http://creativecommons.org/licenses/by/4.0/.

\section{References}

Al-Hakkani, M. F. (2019). Guideline of inductively coupled plasma mass spectrometry "ICP-MS": Fundamentals, practices, determination of the limits, quality control, and method validation parameters. SN Applied Sciences, 1, 791. https://doi.org/10.1007/s42452-019-0825-5

Amato, F., Querol, X., Johansson, C., Nagl, C., \& Alastuey, A. (2010). A review on the effectiveness of street sweeping, washing and dust suppressants as urban PM control methods. Science of the Total Environment, 408, 3070-3084. https://doi.org/10.1016/j.scitotenv.2010.04.025

Aschner, J. L., \& Aschner, M. (2005). Nutritional aspects of manganese homeostasis. Molecular Aspects of Medicine, 26, 353-362. https://doi.org/10.1016/j.mam.2005.07.003

Bäckström, M., Nilsson, U., Häkansson, K., Allard, B., \& Karlsson, S. (2003). Speciation of heavy metals in road runoff and roadside total deposition. Water, Air, and Soil Pollution, 147, 343-366.

Barbosa, F., Tanus-Santos, J. E., Gerlach, R. F., \& Parsons, P. J. (2005). A critical review of biomarkers used for monitoring human exposure to lead: Advantages, limitations, and future needs. Environmental Health Perspectives, 113, 1669-1674. https://doi.org/10.1289/ehp.7917

Batáriová, A., Spěváčková, V., Beneš, B., Čejchanová, M., Šmíd, J., \& Černá, M. (2006). Blood and urine levels of $\mathrm{Pb}, \mathrm{Cd}$ and $\mathrm{Hg}$ in the general population of the Czech Republic and proposed reference values. International Journal of Hygiene and Environmental Health, 209, 359366. https://doi.org/10.1016/j.ijheh.2006.02.005

Bauer, J. A., Devick, K. L., Bobb, J. F., Coull, B. A., Bellinger, D., Benedetti, C., Cagna, G., Fedrighi, C., Guazzetti, S., Oppini, M., Placidi, D., Webster, T. F., White, R. F., Yang, Q., Zoni, S., Wright, R. O., Smith, D. R., Lucchini, R. G., \& Henn, B. C. (2020). Associations of a metal mixture measured in multiple biomarkers with IQ: Evidence from italian adolescents living near ferroalloy industry. Environmental Health Perspectives, 128, 097002-1-09700212. https://doi.org/10.1289/EHP6803

Bocca, B., Madeddu, R., Asara, Y., Tolu, P., Marchal, J. A., \& Forte, G. (2011). Assessment of reference ranges for blood $\mathrm{Cu}, \mathrm{Mn}, \mathrm{Se}$ and $\mathrm{Zn}$ in a selected Italian population. Journal of Trace Elements in Medicine and Biology, 25, 19-26. https://doi.org/10.1016/j.jtemb.2010.12.004

Boente, C., Martín-Méndez, I., Bel-Lán, A., \& Gallego, J. R. (2020). A novel and synergistic geostatistical approach to identify sources and cores of Potentially Toxic Elements in soils: An application in the region of Cantabria (Northern Spain). Journal of Geochemical Exploration, 208, 106397. https://doi.org/10.1016/j.gexplo.2019.106397

Butler, L., Gennings, C., Peli, M., Borgese, L., Placidi, D., Zimmerman, N., Hsu, H. H. L., Coull, B. A., Wright, R. O., Smith, D. R., Lucchini, R. G., \& Claus Henn, B. (2019). Assessing the contributions of metals in environmental media to exposure biomarkers in a region of ferroalloy industry. Journal of Exposure Science and Environmental Epidemiology, 29, 674-687. https://doi.org/10. 1038/s41370-018-0081-6

Cañas, A. I., Cervantes-Amat, M., Esteban, M., Ruiz-Moraga, M., Pérez-Gómez, B., Mayor, J., Castaño, A., Aleixandre, J. L., Aragonés, N., Bartolomé, M., Calvo, E., Cortés, M. V., Cutanda, F., Huetos, O., Jiménez, J. A., López-Abente, G., López-Herranz, A., Méndez, C. F., Molina, M. A., ... Sánchez, J. (2014). Blood lead levels in a representative sample of the Spanish adult population: The BIOAMBIENT.ES project. International Journal of Hygiene and Environmental Health, 217, 452-459. https://doi.org/10. 1016/j.ijheh.2013.09.001

Ceballos, D. M., Young, A. S., Allen, J. G., Specht, A. J., Nguyen, V. T., Craig, J. A., Miller, M., \& Webster, T. F. (2021). Exposures in nail salons to trace elements in nail polish from impurities or pigment ingredients - A pilot study. International Journal of Hygiene and Environmental Health. https://doi.org/10.1016/j.ijheh.2020.113687

Coelho, P., Costa, S., Costa, C., Silva, S., Walter, A., Ranville, J., Pastorinho, M. R., Harrington, C., Taylor, A., Dall'Armi, V., Zoffoli, R., Candeias, C., da Silva, E. F., Bonassi, S., Laffon, B., \& Teixeira, J. P. (2014). Biomonitoring of several toxic metal(loid)s in different biological matrices from environmentally and occupationally exposed populations from Panasqueira mine area, Portugal. Environmental Geochemistry and Health, 36, 255269. https://doi.org/10.1007/s10653-013-9562-7

Coetzee, D. J., McGovern, P. M., Rao, R., Harnack, L. J., Georgieff, M. K., \& Stepanov, I. (2016). Measuring the impact of manganese exposure on children's neurodevelopment: Advances and research gaps in biomarker-based approaches. Environmental Health, 15, 1-20. https://doi. org/10.1186/s12940-016-0174-4

Eastman, R. R., Jursa, T. P., Benedetti, C., Lucchini, R. G., \& Smith, D. R. (2013). Hair as a biomarker of environmental manganese exposure. Environmental Science and Technology, 47, 1629-1637. https://doi.org/10.1021/es303 5297

European Parliament and Council of the European Union. (2009). Regulation (EC) No 1223/2009 of the European Parliament and of the Council of 30 November 2009 on cosmetic products, Official Journal of the European Union.

Expósito, A., Markiv, B., Ruiz-Azcona, L., Santibáñez, M., \& Fernández-Olmo, I. (2021). Understanding how methodological aspects affect the release of trace metal(loid)s from urban dust in inhalation bioaccessibility tests. Chemosphere, 267, 129181. https://doi.org/10.1016/j.chemo sphere.2020.129181

Fernández-Olmo, I., Mantecón, P., Markiv, B., RuizAzcona, L., \& Santibáñez, M. (2021). A review on the 
environmental exposure to airborne manganese, biomonitoring, and neurological/neuropsychological outcomes. Reviews of Environmental Contamination and Toxicology, 246, 85-130. https://doi.org/10.1007/398_2020_46

Ferreira, A. P. S. S., Pereira, E. C., Salles, F. J., da Silva, F. F., Batista, B. L., Handakas, E., \& Olympio, K. P. K. (2019). Home-based and informal work exposes the families to high levels of potentially toxic elements. Chemosphere, 218, 319-327. https://doi.org/10.1016/j.chemosphere. 2018.11.083

Freire, C., Koifman, R. J., Fujimoto, D., de Oliveira Souza, V. C., Barbosa, F., \& Koifman, S. (2015). Reference values of cadmium, arsenic and manganese in blood and factors associated with exposure levels among adult population of Rio Branco, Acre, Brazil. Chemosphere, 128, 70-78. https://doi.org/10.1016/j.chemosphere.2014.12.083

Fulk, F., Haynes, E. N., Hilbert, T. J., Brown, D., Petersen, D., \& Reponen, T. (2016). Comparison of stationary and personal air sampling with an air dispersion model for children's ambient exposure to manganese. Journal of Exposure Science and Environmental Epidemiology, 26, 494-502. https://doi.org/10.1038/jes.2016.30

Godfrey, S., Staite, W., Bowtell, P., \& Marsh, J. (2013). Metals in female scalp hair globally and its impact on perceived hair health. International Journal of Cosmetic Science, 35, 264-271. https://doi.org/10.1111/ics.12033

González-Antuña, A., Camacho, M., Henríquez-Hernández, L. A., Boada, L. D., Almeida-González, M., Zumbado, M., \& Luzardo, O. P. (2017). Simultaneous quantification of 49 elements associated to e-waste in human blood by ICPMS for routine analysis. MethodsX, 4, 328-334. https:// doi.org/10.1016/j.mex.2017.10.001

Grange, S. K. (2014). Technical note: Averaging wind speeds and directions. https://doi.org/10.13140/RG.2.1.3349. 2006

Gurol, K. C., Aschner, M., Smith, D. R., \& Mukhopadhyay, S. (2022). Role of excretion in manganese homeostasis and neurotoxicity: A historical perspective. American Journal of Physiology-Gastrointestinal and Liver Physiology, 322, G79-G92. https://doi.org/10.1152/ajpgi.00299.2021

Hassani, H., Golbabaei, F., Shirkhanloo, H., \& Tehrani-Doust, M. (2016). Relations of biomarkers of manganese exposure and neuropsychological effects among welders and ferroalloy smelters. Industrial Health, 54, 79-86. https:// doi.org/10.2486/indhealth.2014-0250

Haynes, E. N., Heckel, P., Ryan, P., Roda, S., Leung, Y. K., Sebastian, K., \& Succop, P. (2010). Environmental manganese exposure in residents living near a ferromanganese refinery in Southeast Ohio: A pilot study. Neurotoxicology, 31, 468-474. https://doi.org/10.1016/j.neuro.2009. 10.011

Haynes, E. N., Ryan, P., Chen, A., Brown, D., Roda, S., Kuhnell, P., Wittberg, D., Terrell, M., \& Reponen, T. (2012). Assessment of personal exposure to manganese in children living near a ferromanganese refinery. Science of the Total Environment, 427-428, 19-25. https://doi.org/10. 1016/j.scitotenv.2012.03.037

Haynes, E. N., Sucharew, H., Kuhnell, P., Alden, J., Barnas, M., Wright, R. O., Parsons, P. J., Aldous, K. M., Praamsma, M. L., Beidler, C., \& Dietrich, K. N. (2015). Manganese exposure and neurocognitive outcomes in rural school-age children: The communities actively researching exposure study (Ohio, USA). Environmental Health Perspectives, 123, 1066-1071. https://doi.org/10.1289/ehp.1408993

Henríquez-Hernández, L. A., Boada, L. D., Carranza, C., Pérez-Arellano, J. L., González-Antuña, A., Camacho, M., Almeida-González, M., Zumbado, M., \& Luzardo, O. P. (2017). Blood levels of toxic metals and rare earth elements commonly found in e-waste may exert subtle effects on hemoglobin concentration in sub-Saharan immigrants. Environment International, 109, 20-28. https://doi.org/10.1016/j.envint.2017.08.023

Henríquez-Hernández, L. A., González-Antuña, A., Boada, L. D., Carranza, C., Pérez-Arellano, J. L., AlmeidaGonzález, M., Camacho, M., Zumbado, M., FernándezFuertes, F., Tapia-Martín, M., \& Luzardo, O. P. (2018). Pattern of blood concentrations of 47 elements in two populations from the same geographical area but with different geological origin and lifestyles: Canary Islands (Spain) vs. Morocco. Science of the Total Environment, 636, 709-716. https://doi.org/10.1016/j.scitotenv.2018. 04.311

Hernández-Pellón, A., \& Fernández-Olmo, I. (2019). Using multi-site data to apportion PM-bound metal(loid)s: Impact of a manganese alloy plant in an urban area. Science of the Total Environment, 651, 1476-1488. https:// doi.org/10.1016/j.scitotenv.2018.09.261

Hernandez-Pellón, A., Fernandez-Olmo, I., Ledoux, F., Courcot, L., \& Courcot, D. (2017). Characterization of manganese-bearing particles in the vicinities of a manganese alloy plant. Chemosphere, 175, 411-424. https:// doi.org/10.1016/j.chemosphere.2017.02.056

Hernández-Pellón, A., Nischkauer, W., Limbeck, A., \& Fernández-Olmo, I. (2018). Metal(loid) bioaccessibility and inhalation risk assessment: A comparison between an urban and an industrial area. Environmental Research, 165, 140-149. https://doi.org/10.1016/j. envres.2018.04.014

Jiang, Y., Zheng, W., Long, L., Zhao, W., Li, X., Mo, X., Lu, J., Fu, X., Li, W., Liu, S., Long, Q., Huang, J., \& Pira, E. (2007). Brain magnetic resonance imaging and manganese concentrations in red blood cells of smelting workers: Search for biomarkers of manganese exposure. Neurotoxicology, 28, 126-135. https://doi.org/10.1016/j. neuro.2006.08.005

Johansson, C., Norman, M., \& Burman, L. (2009). Road traffic emission factors for heavy metals. Atmospheric Environment, 43, 4681-4688. https://doi.org/10.1016/j. atmosenv.2008.10.024

Jursa, T., Stein, C. R., \& Smith, D. R. (2018). Determinants of Hair Manganese, lead, cadmium and arsenic levels in environmentally exposed children. Toxics, 6, 12-14. https://doi.org/10.3390/toxics6020019

Kelly, F. J., \& Fussell, J. C. (2012). Size, source and chemical composition as determinants of toxicity attributable to ambient particulate matter. Atmospheric Environment, 60, 504-526. https://doi.org/10.1016/j.atmosenv. 2012.06.039

Kim, G., Lee, H. S., Bang, J. S., Kim, B., Ko, D., \& Yang, M. (2015). A current review for biological monitoring of manganese with exposure, susceptibility, and response biomarkers. Journal of Environmental Science and Health 
- Part C Environmental Carcinogenesis and Ecotoxicology Reviews, 33, 229-254. https://doi.org/10.1080/10590 501.2015.1030530

Kim, H. J., Lim, H. S., Lee, K. R., Choi, M. H., Kang, N. M., Lee, C. H., Oh, E. J., \& Park, H. K. (2017). Determination of trace metal levels in the general population of Korea. International Journal of Environmental Research and Public Health. https://doi.org/10.3390/ijerph14070702

Levin-Schwartz, Y., Claus Henn, B., Gennings, C., Coull, B. A., Placidi, D., Horton, M. K., Smith, D. R., Lucchini, R. G., \& Wright, R. O. (2021). Integrated measures of lead and manganese exposure improve estimation of their joint effects on cognition in Italian school-age children. Environment International, 146, 106312. https://doi.org/10. 1016/j.envint.2020.106312

Maret, W. (2016). The metals in the biological periodic system of the elements: Concepts and conjectures. International Journal of Molecular Sciences, 17, 1-8. https://doi.org/10. 3390/ijms17010066

Menezes-Filho, J. A., Paes, C. R., Ângela, Â. M., Moreira, J. C., Sarcinelli, P. N., \& Mergler, D. (2009). High levels of hair manganese in children living in the vicinity of a ferromanganese alloy production plant. Neurotoxicology, 30, 1207-1213. https://doi.org/10.1016/j.neuro.2009.04.005

Mohmand, J., Eqani, S. A. M. A. S., Fasola, M., Alamdar, A., Mustafa, I., Ali, N., Liu, L., Peng, S., \& Shen, H. (2015). Human exposure to toxic metals via contaminated dust: Bio-accumulation trends and their potential risk estimation. Chemosphere, 132, 142-151. https://doi.org/10. 1016/j.chemosphere.2015.03.004

Mukhtar, A., \& Limbeck, A. (2013). Recent developments in assessment of bio-accessible trace metal fractions in airborne particulate matter: A review. Analytica Chimica Acta, 774, 11-25. https://doi.org/10.1016/j.aca.2013.02. 008

Nakaona, L., Maseka, K. K., Hamilton, E. M., \& Watts, M. J. (2020). Using human hair and nails as biomarkers to assess exposure of potentially harmful elements to populations living near mine waste dumps. Environmental Geochemistry and Health, 42, 1197-1209. https://doi.org/ 10.1007/s10653-019-00376-6

Nisse, C., Tagne-Fotso, R., Howsam, M., Richeval, C., Labat, L., \& Leroyer, A. (2017). Blood and urinary levels of metals and metalloids in the general adult population of Northern France: The IMEPOGE study, 2008-2010. International Journal of Hygiene and Environmental Health, 220, 341-363. https://doi.org/10.1016/j.ijheh. 2016.09.020

Olympio, K. P. K., Ferreira, A. P. S. S., Rodrigues, M. H. C., Luz, M. S., Albuquerque, L. G. R., Barbosa, J. F., Cardoso, M. R. A., Oliveira, P. V., \& Buzalaf, M. A. R. (2020). Are fingernail lead levels a reliable biomarker of lead internal dose? Journal of Trace Elements in Medicine and Biology, 62, 126576. https://doi.org/10.1016/j.jtemb. 2020.126576

Otero-Pregigueiro, D., Hernández-Pellón, A., Borge, R., \& Fernández-Olmo, I. (2018). Estimation of PM10-bound manganese concentration near a ferromanganese alloy plant by atmospheric dispersion modelling. Science of the Total Environment, 627, 534-543. https://doi.org/10. 1016/j.scitotenv.2018.01.246
Parhizkar, G., Khalili Doroodzani, A., Dobaradaran, S., Ramavandi, B., Hashemi, S. E., Raeisi, A., Nabipour, I., Keshmiri, S., Darabi, A., Afrashte, S., Khamisipour, G., \& Keshtkar, M. (2021). Childhood exposure to metal(loid) $\mathrm{s}$ in industrial and urban areas along the Persian Gulf using toenail tissue as a biomarker. Environmental Pollution, 291, 118090. https://doi.org/10.1016/j.envpol.2021. 118090

Prasad, V. D., Shireen, S., Ramana, G. V., \& Gupta, T. S. (2014). Assessment of copper, ceruloplasmin, total proteins and albumin in gestational hypertension. IOSR Journal of Dental and Medical Sciences, 13, 101-104. https://doi.org/10. 9790/0853-1344101104

Riojas-Rodríguez, H., Solís-Vivanco, R., Schilmann, A., Montes, S., Rodríguez, S., Ríos, C., \& Rodríguez-Agudelo, Y. (2010). Intellectual function in Mexican children living in a mining area and environmentally exposed to manganese. Environmental Health Perspectives, 118, 1465-1470. https://doi.org/10.1289/ehp.0901229

Rodrigues, J. L. G., Bandeira, M. J., Araújo, C. F. S., dos Santos, N. R., Anjos, A. L. S., Koin, N. L., Pereira, L. C., Oliveira, S. S. P., Mergler, D., \& Menezes-Filho, J. A. (2018). Manganese and lead levels in settled dust in elementary schools are correlated with biomarkers of exposure in school-aged children. Environmental Pollution, 236, 1004-1013. https:// doi.org/10.1016/j.envpol.2017.10.132

Roth, J. A. (2006). Homeostatic and toxic mechanisms regulating manganese uptake, retention, and elimination. Biological Research, 39, 45-57. https://doi.org/10.4067/S0716-97602 006000100006

Ruiz-Azcona, L., Markiv, B., Expósito, A., González-Aramburu, I., Sierra, M., Fernández-Olmo, I., \& Santibáñez, M. (2021). Biomonitoring and bioaccessibility of environmental airborne manganese in relation to motor function in a healthy adult population. Neurotoxicology, 87, 195-207. https://doi. org/10.1016/j.neuro.2021.10.005

Santos-Burgoa, C., Rios, C., Mercado, L. A., Arechiga-Serrano, R., Cano-Valle, F., Eden-Wynter, R. A., Texcalac-Sangrador, J. L., Villa-Barragan, J. P., Rodriguez-Agudelo, Y., \& Montes, S. (2001). Exposure to manganese: Health effects on the general population, a pilot study in Central Mexico. Environmental Research, 85, 90-104. https://doi.org/10. 1006/enrs.2000.4108

Saravanabhavan, G., Werry, K., Walker, M., Haines, D., Malowany, M., \& Khoury, C. (2017). Human biomonitoring reference values for metals and trace elements in blood and urine derived from the Canadian Health Measures Survey 20072013. International Journal of Hygiene and Environmental Health, 220, 189-200. https://doi.org/10.1016/j.ijheh.2016. 10.006

Schulz, C., Wilhelm, M., Heudorf, U., \& Kolossa-Gehring, M. (2011). Update of the reference and HBM values derived by the German Human Biomonitoring Commission. International Journal of Hygiene and Environmental Health, 215, 26-35. https://doi.org/10.1016/j.ijheh.2011.06.007

Stojsavljević, A., Borković-Mitić, S., Vujotić, L., Grujičić, D., Gavrović-Jankulović, M., \& Manojlović, D. (2019). The human biomonitoring study in Serbia: Background levels for arsenic, cadmium, lead, thorium and uranium in the whole blood of adult Serbian population. Ecotoxicology 
and Environmental Safety, 169, 402-409. https://doi.org/10. 1016/j.ecoenv.2018.11.043

Sukumar, A., \& Subramanian, R. (2007). Relative element levels in the paired samples of scalp hair and fingernails of patients from New Delhi. Science of the Total Environment, 372, 474-479. https://doi.org/10.1016/j.scitotenv.2006.10.020

Tratnik, J. S., Falnoga, I., Mazej, D., Kocman, D., Fajon, V., Jagodic, M., Stajnko, A., Trdin, A., Šlejkovec, Z., Jeran, Z., Osredkar, J., Sešek-Briški, A., Krsnik, M., Kobal, A. B., Kononenko, L., \& Horvat, M. (2019). Results of the first national human biomonitoring in Slovenia: Trace elements in men and lactating women, predictors of exposure and reference values. International Journal of Hygiene and Environmental Health, 222, 563-582. https://doi.org/10.1016/j. ijheh.2019.02.008

US Department of Health and Human Services. (2018). Fourth National Report on Human Exposure to Environmental Chemicals.

Van Neste, D. J. J., \& Rushton, D. H. (2016). Gender differences in scalp hair growth rates are maintained but reduced in pattern hair loss compared to controls. Skin Research and Technology, 22, 363-369. https://doi.org/10.1111/srt.12274

Viana, G. F. D. S., de Carvalho, C. F., Nunes, L. S., Rodrigues, J. L. G., Ribeiro, N. S., de Almeida, D. A., Dutra Ferreira, J. R., Abreu, N., \& Menezes-Filho, J. A. (2014). Noninvasive biomarkers of manganese exposure and neuropsychological effects in environmentally exposed adults in Brazil. Toxicology Letters, 231, 169-178. https://doi.org/10.1016/j.toxlet. 2014.06.018

Vimercati, L., Baldassarre, A., Gatti, M. F., Gagliardi, T., Serinelli, M., De Maria, L., Caputi, A., Dirodi, A. A., Galise, I., Cuccaro, F., \& Assennato, G. (2016). Non-occupational exposure to heavy metals of the residents of an industrial area and biomonitoring. Environmental Monitoring and Assessment. https://doi.org/10.1007/s10661-016-5693-5

Wong, S. L., \& Lye, E. J. D. (2008). Lead, mercury and cadmium levels in Canadians. Statitics Canada. Health Reports, 19, 31-36.
Yaemsiri, S., Hou, N., Slining, M. M., \& He, K. (2010). Growth rate of human fingernails and toenails in healthy American young adults. Journal of the European Academy of Dermatology and Venereology, 24, 420-423. https://doi.org/10. 1111/j.1468-3083.2009.03426.x

Zeng, H. L., Li, H., Lu, J., Guan, Q., \& Cheng, L. (2019). Assessment of 12 Metals and Metalloids in Blood of General Populations Living in Wuhan of China by ICP-MS. Biological Trace Element Research, 189, 344-353. https://doi.org/10. 1007/s12011-018-1486-8

Zhang, L. L., Lu, L., Pan, Y. J., Ding, C. G., Xu, D. Y., Huang, C. F., Pan, X. F., \& Zheng, W. (2015). Baseline blood levels of manganese, lead, cadmium, copper, and zinc in residents of Beijing suburb. Environmental Research, 140, 10-17. https://doi.org/10.1016/j.envres.2015.03.008

Zheng, W., Fu, S. X., Dydak, U., \& Cowan, D. M. (2011). Biomarkers of manganese intoxication. Neurotoxicology, 32, 1-8. https://doi.org/10.1016/j.neuro.2010.10.002

Zoroddu, M. A., Aaseth, J., Crisponi, G., Medici, S., Peana, M., \& Nurchi, V. M. (2019). The essential metals for humans: A brief overview. Journal of Inorganic Biochemistry, 195, 120-129. https://doi.org/10.1016/j.jinorgbio.2019.03.013

Zubero, M. B., Aurrekoetxea, J. J., Ibarluzea, J. M., Arenaza, M. J., Rodríguez, C., \& Sáenz, J. R. (2010). Heavy metal levels $(\mathrm{Pb}, \mathrm{Cd}, \mathrm{Cr}$ and $\mathrm{Hg})$ in the adult general population near an urban solid waste incinerator. Science of the Total Environment, 408, 4468-4474. https://doi.org/10.1016/j.scitotenv. 2010.07.003

Publisher's Note Springer Nature remains neutral with regard to jurisdictional claims in published maps and institutional affiliations. 